The Emergence of Information Sharing

in Credit Markets

Martin Brown and Christian Zehnder

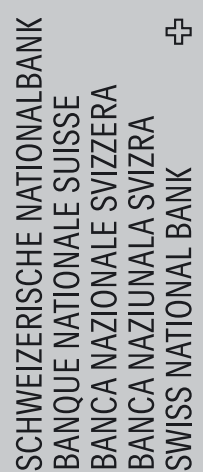

U

(1)

(1)

ro

잉

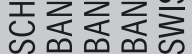

م 
The views expressed in this paper are those of the author(s) and do not necessarily represent those of the Swiss National Bank. Working Papers describe research in progress. Their aim is to elicit comments and to further debate.

ISSN 1660-7716 (printed version)

ISSN 1660-7724 (online version)

๑ 2008 by Swiss National Bank, Börsenstrasse 15, P.0. Box, CH-8022 Zurich 


\title{
The Emergence of Information Sharing in Credit Markets*
}

\author{
Martin Brown ${ }^{\dagger}$ and Christian Zehnder ${ }^{\ddagger}$
}

November 2007

\begin{abstract}
We examine how asymmetric information and competition in the credit market affect voluntary information sharing between lenders. We study an experimental credit market in which information sharing can help lenders to distinguish good borrowers from bad ones, because borrowers may exogenously switch locations. Lenders are, however, engaged in spatial competition, and thus may lose market power by sharing information with competitors. Our results suggest that asymmetric information in the credit market increases the frequency of information sharing between lenders significantly. Competition between lenders reduces information sharing, but the impact of competition seems to be only of second order importance.
\end{abstract}

*We thank Paolo Mistrulli, Steven Ongena, Juan Ignacio Pena, and an anonymous referee, as well as seminar participants at the University of Zurich, HEC Lausanne, the 2007 FMA European conference, and the 2007 EEA annual meeting for helpful comments. We further thank Franziska Heusi for providing excellent research assistance. Zehnder gratefully acknowledges financial support by the national center of competence in research on "Financial Valuation and Risk Management". The national centers in research are managed by the Swiss National Science Foundation on behalf of the federal authorities. The views expressed in this paper do not necessarily reflect those of the Swiss National Bank.

$\dagger^{\dagger}$ Swiss National Bank, Börsenstrasse 15, CH-8022 Zurich, martin.brown@snb.ch.

${ }^{\ddagger}$ Harvard Business School, Soldiers Field, Boston, MA 02163, czehnder@hbs.edu. 


\section{Introduction}

The systematic use of credit reports in assessing loan applications is one of the most remarkable developments in retail banking. Today, loan approvals no longer take days or weeks, but are made in minutes, thanks to information derived from credit reports. Over the past 30 years, the number of reports issued by credit bureaus in the United States has increased ten-fold, so that nowadays over 3 million credit reports are issued on a daily basis (Hunt, 2005). Beyond the United States, the credit reporting industry has also seen substantial developments. Examining data for 129 countries, Djankov et al. (2007) show that the number of countries with a public credit registry increased from $21 \%$ in 1978 to $53 \%$ in 2003 , while the number of countries with at least one private credit bureau increased from $16 \%$ to $41 \%$ over the same period.

In this paper, we provide empirical evidence on the emergence of information sharing through private credit bureaus. Private credit bureaus rely on voluntary information exchange between lenders, which typically involves a trade-off. On the one hand, lenders benefit from information sharing, as it helps them to select good from bad loan applicants (Pagano and Jappelli, 1993). Moreover, information sharing can overcome moral hazard on the part of borrowers, motivating them to exert greater effort in projects (Vercammen, 1995; Padilla and Pagano, 2000, and repay loans (Klein, 1992). On the other hand, sharing information may expose lenders to increased competition because they release private information about their existing clients. Banks may therefore be wary of sharing information in competitive credit markets, and may be particularly reluctant to share information with close competitors (Pagano and Jappelli, 1993). ${ }^{1}$

Can competition in the banking sector hinder the emergence of information sharing in markets where adverse selection would make it valuable from a social point of view? This is an empirical question, and the answer depends on the relative impact of adverse selection and lender competition on information sharing behavior. So far, there is little evidence on these two forces that drive voluntary information sharing. Historical records show that credit reporting in the United States did initially emerge among non-competing lenders (Olegario, 2003). Anecdotal evidence from Russia also demonstrates the reluctance of banks to participate in the same credit bureau as their rivals. After the introduction of a law in 2005 forcing all lenders to join at least one bureau, many lenders set up their own credit bureaus, in order to avoid sharing information with competitors. ${ }^{2}$ In contrast to this, it is striking that many bureaus collect and distribute information specifically for the consumer credit market, which is arguably one of the most competitive retail

\footnotetext{
${ }^{1}$ In a recent paper, Bouckaert and Degryse (2006) show that the incentives to unilaterally disclose information on default behavior also depend on lenders' inherent market power.

${ }^{2}$ See http://www.interfax.ru/e/B/0/0.html?id_issue $=11383470$.
} 
segments (Hunt, 2005; San José Riestra, 2002). It appears therefore that, at least in consumer credit, the benefits of sharing information may outweigh the costs of increased competition. So far, however, there is no systematic analysis of the driving forces behind information sharing to support this conjecture.

We examine - in a laboratory credit market - how adverse selection and lender competition affect voluntary information sharing between lenders. We implement an experimental credit market which is characterized by adverse selection: Lenders know that there are good and bad borrowers, but they can only identify the type of borrowers in their "home market". Borrowers may switch their location, in which case lenders can only identify the type of entrants to their market if they share information with lenders who are situated in other markets. The higher the probability that borrowers switch location, the more severe the problem of adverse selection, and the stronger the incentives to share information. Our credit market is also characterized by lender competition, which reduces information sharing incentives. We implement a simple form of spatial competition: Each lender has one direct competitor and two lenders with whom he does not compete at all. In such a situation, lenders benefit from sharing information with non-competitors, but lose market power if they share information with direct competitors. The advantage of our experimental approach is that we can exogenously vary both the degree of adverse selection, i.e. borrower mobility, as well as the intensity of competition between lenders. By comparing the outcome across treatments we can therefore identify how exogenous changes in information conditions and lender competition affect the emergence of information sharing. Our experimental approach also allows us to compare the relative impact of adverse selection and lender competition on information sharing behavior.

Our experimental results confirm the hypothesis that adverse selection and lender competition both systematically affect voluntary information sharing. In treatments with high borrower mobility, information sharing between our experimental lenders is more frequent than in (otherwise identical) treatments with low borrower mobility. Similarly, treatments with strong competition between lenders display lower levels of information sharing than (otherwise identical) treatments with weak lender competition. Our results, however, also suggest that the impact of adverse selection on information sharing is much stronger than that of lender competition. An increase in the level of borrower mobility raises the level of information sharing substantially. In contrast, increasing the level of lender competition leads only to a small reduction in information sharing. Our finding, that adverse selection has a stronger impact on information sharing than lender competition, is particulary important for the outcome of markets where both are high, such as in the consumer credit market. In our experiment we find that when potential adverse selection is strong, information sharing between lenders is very frequent even if lenders 
are engaged in intense competition.

Our findings contribute to the growing empirical literature on the role of information sharing in financial market development. Several recent studies have demonstrated that information sharing is beneficial to credit market performance. Credit scoring models based on credit bureau data suggests that the use of credit reports allows lenders to more accurately predict loan defaults (Kallberg and Udell, 2003; Barron and Staten, 2003; Luoto et al., 2007; Powell et al., 2004). Moreover, recent experimental results indicate that information sharing disciplines borrowers to repay loans (Brown and Zehnder, forthcoming). Cross-country evidence, meanwhile, supports the conjecture that information sharing improves credit availability. Aggregate credit market volume is higher in countries where information sharing is more developed (Jappelli and Pagano, 2002; Djankov et al., 2007). Moreover, analyses of firm-level data (Galindo and Miller, 2001; Love and Mylenko, 2003; Brown et al., 2007) show that access to bank credit is easier in countries where credit bureaus or registries exist. While existing evidence confirms that information sharing between lenders is beneficial for credit market performance, there is little evidence examining the circumstances in which credit bureaus emerge. Pagano and Jappelli (1993) show that consumer credit reporting in OECD countries is positively related to household mobility, and thus to potential adverse selection for banks. However, there is, to our knowledge, no systematic evidence on how credit market competition interacts with adverse selection in determining voluntary information sharing. Our experimental results provide a first attempt at closing this gap.

The rest of the paper is organized as follows: Part 2 presents our experimental design and part 3 our predictions. Part 4 presents our results, and part 5 concludes.

\section{Experimental design}

We examine the voluntary exchange of information between lenders in a competitive credit market characterized by asymmetric information. Similar to Pagano and Jappelli (1993), lenders only know the type of borrowers in their home market. As there is a positive probability that borrowers switch locations, lenders may want to exchange information about borrowers. However, as lenders compete for borrowers, information sharing constitutes a trade-off: Should lenders join the bureau in order to gain information on borrowers which may move to their market, or should they stay out of the bureau in order to hide good borrowers in their home market from competitors. 


\subsection{Credit market}

Our credit market is divided into two regions, $A$ and $B$, and in each region there are two sectors. Sectors $S 1$ and $S 2$ are in region A, sectors $S 3$ and $S 4$ are in region B. In each sector there is one lender ( $L 1$ in $S 1, L 2$ in $S 2, L 3$ in $S 3, L 4$ in $S 4$ ), and four entrepreneurs (E1-E4 in $S 1, E 5-E 8$ in $S 2, E 9-E 12$ in $S 3$ and E13-E16 in $S 4$ ). Each entrepreneur requires a loan of $I=100$ points in order to realize a project. In each region there is one good entrepreneur who yields a return of $Y_{g}=300$ points from his project and three bad entrepreneurs who yield an income of $Y_{b}=0$ from their project. Figure 1 provides a graphical representation of our experimental credit market.

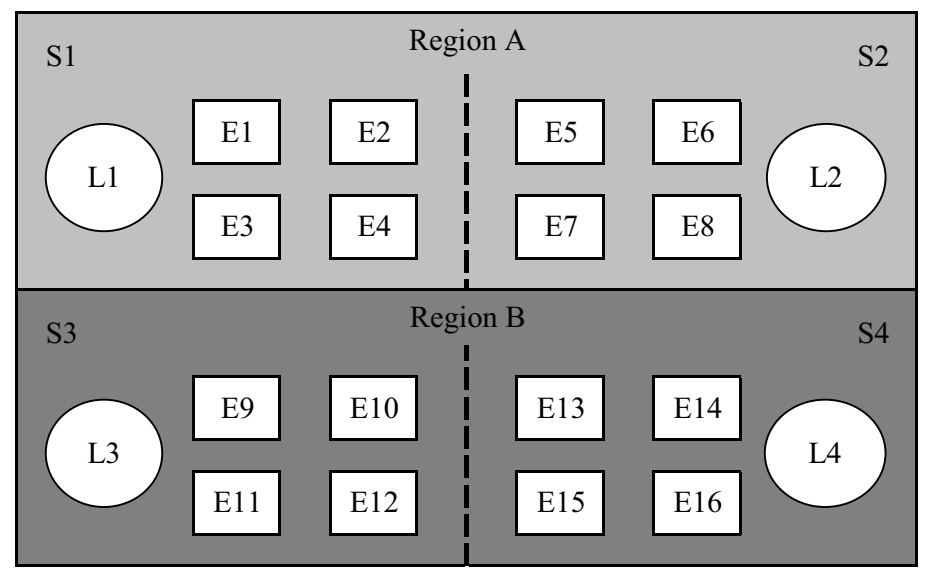

Figure 1: Structure of the credit market

The participants in our experiment all take the role of lenders. Entrepreneurs are simulated. The strategic interaction between our experimental lenders takes place in six phases:

In phase 1, each lender gets to know the type of all four entrepreneurs in his home sector. Which entrepreneur is good in each sector is randomly determined at the beginning of each period. Lenders do not get any information about the entrepreneurs' types in the other three sectors of the credit market.

In phase 2, each lender decides whether to join the credit bureau or not. The two lenders who are in the same region decide sequentially. In each period the "first-mover" for each region is randomly determined. Before deciding whether to join the credit bureau, the "second-mover" in each region is informed about the decision of the first-mover. Neither the first-, nor the second-mover in one region are informed about the decisions of lenders in the other region until after they have made their own decisions. Membership of the credit bureau bears no cost, and information sharing is reciprocal: All members of the 
credit bureau get to know the type of all entrepreneurs from the home sector of all other bureau members. Non-members receive no information on entrepreneurs outside of their home sector. In return, bureau members do not receive information on an entrepreneur if the lender from his home sector does not join the bureau. ${ }^{3}$

In phase 3, entrepreneurs switch sectors with a probability $\alpha$. If entrepreneurs switch their sector, they do so in groups, and switch to the other region. All entrepreneurs from sector $S 1$ move to sector $S 3$ (and vice versa), while all entrepreneurs from sector $S 2$ move to sector $S 4$ (and vice versa). The fact that entrepreneurs switch in groups guarantees that, if they switch, there remain one good entrepreneur and three bad ones in each sector. The fact that entrepreneurs always switch regions simplifies the strategic interaction, as lenders know that if switching occurs they can no longer access any borrower they already have information on. Whether entrepreneurs switch or not is determined by the physical roll of a dice.

In phase 4, lenders simultaneously make credit offers. Before doing so, each lender is informed about which other lenders have joined the credit bureau, and whether the entrepreneurs have switched locations. Each lender can make credit offers to entrepreneurs who at this point in time are situated in the same region. Lenders $L 1$ and $L 2$ can offer credit to any entrepreneur situated in region A. Lenders $L 3$ and $L 4$ can offer credit to any entrepreneur situated in region $\mathrm{B}$. The size of a credit is fixed at $I=100$ points. When making a credit offer, the lender must specify his requested repayment $\tilde{R} \in[100,300]$. In order to make a credit offer to a particular entrepreneur, a lender must select the ID number of the entrepreneur. Each lender is endowed with funds of 200 points in each period, and can therefore make at most two credit offers. As there are two lenders and only two good borrowers per region our design implies competition between lenders for the good entrepreneurs in a region. Intra-regional competition in our experiment is however incomplete. A credit offer to the entrepreneur situated in the home sector of the lender bears no transaction costs $c=0$. In contrast, a credit offer to an entrepreneur in the other sector of the region involves positive transaction costs of $c=T$. Overall our design

\footnotetext{
${ }^{3}$ For the sake of simplicity we fix, by design, the type of potential information sharing which can take place: Lenders can exchange information about the types of borrowers in their home market, and they can do so only on a reciprocal basis. We measure the extent of voluntary information sharing by studying the frequency with which lenders use this available information sharing mechanism. In reality, the extent of information sharing depends not only on how many banks share information, but also on what type of information they exchange. Some credit registries and credit bureaus only enable the exchange of information on loan defaults ("negative information"), while others also facilitate the exchange of information on open credit lines, successful loan repayments and borrower characteristics ("positive information"). Obviously, it would be interesting to study not only how many lenders share information voluntarily, but also what type of information they would choose to share. In our experimental credit market, the only information worth exchanging relates to borrower types, as borrowers cannot default, and they cannot maintain multiple bank relationships.
} 
implements a simple form of spatial competition: Each lender has one direct competitor with whom he competes in an incomplete manner, and two lenders with whom he does not compete at all.

In phase 5, each entrepreneur can accept one of the credit offers made to him. Entrepreneurs in our experiment are programmed to accept the credit offer with the lowest requested repayment. If an entrepreneur receives two credit offers with equal repayment requests he chooses that of the lender from the sector he is situated in. This is common knowledge among lenders. The lenders' repayment requests are enforceable, but we assume that there is limited liability of entrepreneurs. Thus, good entrepreneurs make actual loan repayments of $R=\tilde{R}$, while bad entrepreneur make repayments of 0 .

In phase 6, the lenders get to know the credit market outcome and their payoffs. Lenders also find out the type of each entrepreneur in their region and are informed about all credit offers made by themselves and the other lender in their region. Lenders also get to know which of their credit offers were accepted and their resulting payoff. It is common knowledge that all lender payoffs are calculated in each period as follows:

$$
\pi^{L}= \begin{cases}200, & \text { if no credit offer is accepted } \\ 100+R_{1}-c_{1}, & \text { if one credit offer is accepted } \\ R_{1}-c_{1}+R_{2}-c_{2}, & \text { if two credit offers is accepted }\end{cases}
$$

Each session of our experiment involves 12 participants and lasts 20 periods. As all participants are assigned the role of lenders, there are three identical credit markets in each period with four lenders each. Each period involves a restart of the experiment: Lenders are randomly reassigned to one of the three credit markets, and the location of the good entrepreneur in each sector of each credit market is randomly determined.

\subsection{Treatments and procedures}

We implement four treatments of our experiment. Treatments differ only in the probability of entrepreneurs switching $\alpha$ and the transaction costs of intra-regional lending $T$. In order to study the impact of borrower mobility and lender competition on information sharing we vary both factors independently. We implement treatments in which borrower mobility is high $(\alpha=.75)$ and treatments in which borrower mobility is low $(\alpha=.25)$. For both levels of borrower mobility we implement one treatment in which lending competition is high, because transactions costs of intra-regional lending are low $(T=60)$, and one treatment in which lender competition is low because transaction costs are high $(T=160)$. Table 1 summarizes our experiment design.

In total we conducted 20 experimental sessions, five for each of our four treatments. All experimental subjects were volunteers and each participant could only participate in 
one session (i.e., each subject experienced only one of the treatments). All sessions were conducted in June 2006 and participants were students at the University of Zurich or the ETH Zurich. The computerized experiment was programmed and conducted with the z-Tree experimental software (Fischbacher, 2007). A session lasted approximately ninety minutes. Subjects received a show-up fee of CHF 10 (CHF1.3 $\approx 1.00$ USD in June 2006)and CHF1 additional franc for every 150 points earned during the experiment. On average subjects earned CHF 55 .

Table 1: Experimental Treatments

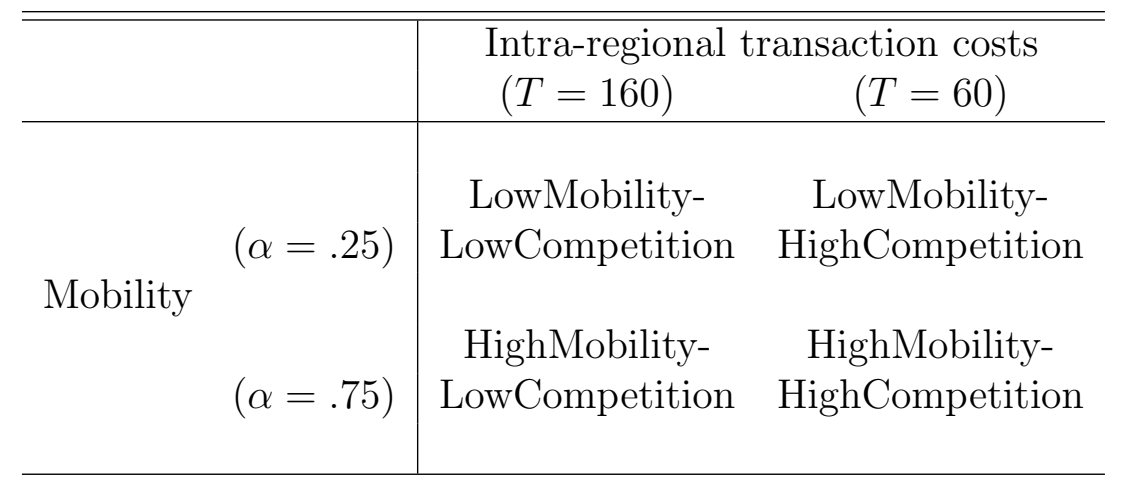

To make sure that all participants fully understand the decision process and the payment structure of the game, each subject had to read a detailed set of instructions before a session was started. After reading the instructions, participants had to pass a test with control questions. No session started before all subjects had correctly answered all control questions. An English version of our instructions is provided in Appendix B. ${ }^{4}$

\section{Predictions}

We derive our predictions by backward induction, assuming that all lenders are riskneutral. We first examine lenders' credit decisions, depending on the information conditions in the market. We then examine the decision of lenders to join the credit bureau. We describe the full set of pure strategy equilibria for our experiment, depending on the mobility of entrepreneurs $\alpha$ and the degree of intra-regional competition determined by $T$. This allows us to make precise predictions for each of our four treatments.

\footnotetext{
${ }^{4}$ The original German instructions, as well as the z-Tree codes are available upon request from the authors.
} 


\subsection{Credit}

No lender will make a credit offer to an entrepreneur he knows is "bad", as he would incur a certain loss of $I=100$ if the entrepreneur is situated in his own sector, and a loss of $100+T$ if the entrepreneur is in the other sector of the region. Furthermore, no lender will lend to an entrepreneur of an unknown type. The expected profit from lending to an unidentified entrepreneur in the same sector is $\pi_{i}^{L}=.25 \cdot Y_{g}-I=-25$. The expected profit from lending to an unidentified entrepreneur in the other sector of the lender's region is consequently also negative $\pi_{i}^{L}=-25-T$. Therefore, from now on we only need to consider offers to entrepreneurs that are known to be good. If a lender knows that he is the only lender in his region who knows that a particular entrepreneur $i$ is good, he will demand the maximum repayment $\tilde{R}_{i}=Y_{g}=300$. He does this because he knows that the entrepreneur will receive no credit offer from his competitor. In this case, the lender's profit from the contract with entrepreneur $i$ is either $\pi_{i}^{L}=Y_{g}-I=200$, if the entrepreneur is in the lender's home sector, or $\pi_{i}^{L}=200-T$ if the entrepreneur is in the other sector of the region. If, however, both lenders in a region know that entrepreneur $i$ is good, price competition implies that each lender will make an offer with a requested

repayment $\tilde{R}_{i}=I+T=100+T$, which is the lowest profitable offer the "outside" lender can make. As, by assumption, entrepreneurs always accept the offer of the home lender in the event of identical repayment requests, the lender situated in the same sector as entrepreneur $i$ will conclude a contract with him and makes a profit of $\pi_{i}^{L}=T$.

\subsection{Information sharing}

In our experiment, decisions to join the credit bureau are made sequentially within regions and simultaneously across regions. Lemma 1 characterizes the best-response behavior of the second-mover lender in each region, given the decision of his competitor and the (unknown) behavior of the two non-competing lenders from the other region.

Lemma 1. (second-mover behavior) i) If the first-mover lender in a region does not join the credit bureau, the second-mover lender is strictly better off by joining, if at least one non-competing lender also joins. If no other lender joins, then the second-mover lender is indifferent between joining and not. ii) If the first-mover lender in a region does join the credit bureau, then the second-mover lender is better off by joining only if $\left(Y_{g}-I\right)(1-\alpha) \leq(1-\alpha+\gamma \alpha) T$, where $\gamma \in\{0 ; .5 ; 1\}$ is the share of non-competing lenders from the other region that join.

Proof. see Appendix A.1.

The intuition behind Lemma 1 is straightforward: i) If a lender's direct competitor is 
not a bureau member, information sharing can only be beneficial. If entrepreneurs switch regions, then being the only bureau member clearly is an advantage if at least one of the lenders in the other region has also joined the bureau. In this case, the lender has exclusive information in its region and can extract monopoly profits from all identified good entrepreneurs. If the entrepreneurs remain in their initial sectors, nothing is lost from joining, as the competitor in the other sector of the region has not joined and will not receive any information. If no other lender joins the credit bureau, a lender can neither benefit nor lose from joining the bureau. ii) If a lender's direct competitor joins, information sharing has beneficial and adverse effects. Whether the net effect of joining is positive or negative depends on three factors: The mobility of borrowers $(\alpha)$, the market power of lenders in their home market $(T)$ and the number of lenders from the other region who join the credit bureau. The net effect of information sharing is more likely to be positive if entrepreneurs switch their location very often, if lenders have strong market power and if the non-competing lenders of the other region join the credit bureau.

Having characterized the best response behavior of the second-mover in each region, we can now characterize profit-maximizing behavior of the first-mover:

Lemma 2. (first-mover behavior) i) The first-mover lender in a region is strictly better off by joining the credit bureau if at least one non-competing lender also joins. ii) If no non-competing lender joins, the first-mover lender is indifferent between joining and not.

Proof. If the first-mover does join the credit bureau he knows that the second-mover will also join if $\left(Y_{g}-I\right)(1-\alpha) \leq(1-\alpha+\gamma \alpha) T$, where $\gamma \in\{0 ; .5 ; 1\}$ is the share of noncompeting lenders that join. Given that under these conditions the second-mover finds it profitable to join and payoffs of lenders are symmetric, the first-mover must also be better off by joining the bureau. If $\left(Y_{g}-I\right)(1-\alpha)>(1-\alpha+\gamma \alpha) T$, the second-mover would not join after the first-mover joins and the first-mover is at least better off by joining the credit bureau than by not doing so. He is strictly better off if at least one non-competing lender joins $\gamma \in\{0.5 ; 1\}$ (see proof of Lemma 1 ).

Lemma 1 and 2 allow us to characterize the full set of Nash equilibria for our experiment, depending on the "mobility" of entrepreneurs $\alpha$ and intra-regional transaction costs $T$. For all combinations of parameters there exists an equilibrium in which no lender joins the credit bureau. If no other lender joins the credit bureau it is a (weakly) best response for the remaining lender not to join as well. However, the no sharing equilibrium is not trembling-hand perfect in the sense of Selten (1975). ${ }^{5}$ We therefore neglect these equilibria in the rest of the paper.

\footnotetext{
${ }^{5}$ Intuitively, the problem can be understood as follows: In the no sharing equilibrium all played strategies are only weakly best responses, i.e., if no other lender joins, lenders are indifferent between joining and not joining. Thus, if we assume that the lenders through a "slip of the hand" or tremble,
} 
Proposition 1 summarizes the conditions under which full sharing of information (both the first-mover and second-mover lender per region join the credit bureau) can be sustained. The proposition shows that full information sharing can be sustained if borrowers are sufficiently mobile (high $\alpha$ ) and/or the competition from other lenders is sufficiently weak (high transaction costs $T$ ).

Proposition 1. There exists a Nash equilibrium in which all lenders join the credit bureau with certainty if and only if $\left(Y_{g}-I\right)(1-\alpha) \leq T$.

Proof. If both lenders in region B join the credit bureau we have $\gamma=1$. Now consider the best response of the second-mover lender in region $\mathrm{A}$ if the first-mover has joined the credit bureau. From Lemma 1 we know that with $\gamma=1$ the best-response for the lender is to join if $\left(Y_{g}-I\right)(1-\alpha) \leq T$. Furthermore, from Lemma 2 we know that if both non-competing lenders join the credit bureau, the first-mover lender is strictly better off by joining as well.

Proposition 2 summarizes the conditions under which partial sharing of information can be sustained in equilibrium; i.e. only the first-mover lender per region joins the credit bureau. The proposition shows that when the market power of lenders in their home sector is weak and/or when borrowers are rather immobile, equilibria exist in which no lender shares information with direct competitors.

Proposition 2. There exists a Nash equilibrium in which only the first-mover lender per region joins the credit bureau if and only if $\left(Y_{g}-I\right)(1-\alpha)>\left(1-\frac{1}{2} \alpha\right) T$.

Proof. Suppose that one non-competing lender joins the credit bureau so that $\gamma=\frac{1}{2}$. Now consider the best response of the second-mover lender if the first-mover has joined the credit bureau. From Lemma 1 it is clear that with $\gamma=\frac{1}{2}$ the best-response for the lender is not to join if $\left(Y_{g}-I\right)(1-\alpha)>\left(1-\frac{1}{2} \alpha\right) T$. From Lemma 2 we further know that if one non-competing lender joins the credit bureau, the first-mover lender is strictly better off by joining as well.

Proposition 1 replicates the main findings of Pagano and Jappelli (1993): the level of information sharing is positively related to the "mobility" of borrowers and negatively related to competition in the credit market. In contrast to their analysis, however, spatial competition between lenders in our experiment yields two additional interesting predictions: ${ }^{6}$

may choose unintended strategies with a negligible but positive probability, then not joining is strictly dominated by joining. In different words, if there is only the slightest probability that one of the lenders in the other region may join, no sharing is no longer an equilibrium.

${ }^{6}$ Pagano and Jappelli (1993) do assume in their model that some lenders are more distant than others, but do not analyze the consequences of this assumption for information sharing equilibria. 
1. When market conditions cannot sustain information sharing between all lenders, there exist partial sharing equilibria in which lenders exchange information only with non-competitors (see Proposition 2).

2. Even when full information sharing can be sustained, partial information sharing may arise due to a "coordination failure" among non-competing lenders. Comparing Propositions 1 and 2 we see that there exists a range of parameters $(G-I)(1-\alpha)<$ $T<(G-I)(1-\alpha) \frac{2}{2-\alpha}$ for which both full-sharing and partial-sharing of information among lenders is feasible. ${ }^{7}$

The intuition for the first result comes from the fact that in our type of spatial competition it does not hurt to share information with non-competitors. As soon as at least one lender in the other region joins there is a strict incentive for at least one lender in a region to join as well, i.e., there must always be an equilibrium in which at least two noncompeting lenders join the credit bureau. ${ }^{8}$ The intuition for the second result comes from the fact that under spatial competition the value of joining the credit bureau depends on how many non-competitors join. Under some parameter constellations it may be the case that the second-mover lender in region A will join only if both non-competing lenders from region $\mathrm{B}$ join, but not if only one of them is a member of the credit bureau. There thus exists the potential for "coordination failure" among non-competing lenders, leading to multiple equilibria for a considerable range of parameter constellations. Note that this second result relies not only on spatial competition, but also on our assumption that the decisions to join the credit bureau are simultaneous across regions. If the decisions of lenders to join the credit bureau are made fully sequentially, the potential for "coordination failure" between non-competing lenders does not arise. However, fully sequential joining decisions imply that all lenders can perfectly observe the behavior of all other potential members of the credit bureau. It is rather unlikely that this will be the case in

\footnotetext{
${ }^{7}$ For the same range of parameters there also exists one mixed-strategy equilibrium. In this equilibrium the first-movers in both regions join the bureau, while the second-movers both join with a positive probability.

${ }^{8}$ An alternative type of spatial competition would be to assume symmetric, imperfect competition with costs of $c=T$ for all cross-sectoral transactions. In this case, we would yield for each parameter constellation either a unique full-sharing or a no-sharing equilibrium. To see this, suppose that it is the best response for lender $j$ to join the credit bureau if one other lender $i$ also joins. In this case, it must be profit-maximizing for both other lenders in the credit market to join the bureau as the benefits of joining increase with the number of other participants, while the costs do not. Thus if all lenders compete with each other (imperfectly at transaction costs $T$ ), there exits for each parameter constellation either a unique full-sharing or a no-sharing equilibrium. Despite the improvements in communication technology we believe, however, that the assumption of "differentiated" competition among lenders is more realistic than to assume that all lenders compete with each other at the same intensity. Degryse and Ongena (2005), for example, showed recently that distance between firms, lenders, and competitor lenders strongly influence loan terms in Belgium.
} 
reality. Another interpretation of fully sequential moves is that a third party can credibly announce that he will approach all potential members sequentially, and that they will be fully bound by their promises to exchange information. In practice, private entrepreneurs do perform this task, and are instrumental in establishing reciprocal credit bureaus (for example Experian or CRIF in Eastern Europe). However, it is highly unlikely that all lenders believe that all other lenders will be approached and will bide by their promises to join. ${ }^{9}$

\subsection{Predictions by treatment}

Applying Proposition 1 we see that a full-sharing equilibrium, in which both lenders in each region join the credit bureau, is feasible in three of our four treatments. The condition $\left(Y_{g}-I\right)(1-\alpha) \leq T$ is fulfilled in the "LowMobility-LowCompetition" treatment $(\alpha=.25 ; T=160)$, in the "HighMobility-HighCompetition" treatment $(\alpha=.75$; $T=60)$, and in the "HighMobility-LowCompetition" treatment $(\alpha=.75 ; T=160)$. Full-sharing is, however, not feasible in our "LowMobility-HighCompetition" treatment $(\alpha=.25 ; T=60)$. By applying Proposition 2 we further see that a partialsharing equilibrium, i.e., only 1 lender per region joins the credit bureau, is feasible in three of our four treatments. The condition $\left(Y_{g}-I\right)(1-\alpha) \geq\left(1-\frac{1}{2} \alpha\right) T$ is fulfilled in the "LowMobility-LowCompetition", "HighMobility-HighCompetition", and "LowMobility-HighCompetition" treatments. Partial-sharing is, however, not feasible in our "HighMobility-LowCompetition" treatment.

Figure 2 displays the predictions for our experiment and illustrates the rationale behind our choice of treatments. We implement two benchmark treatments in which only one equilibrium type is feasible. In the "HighMobility-LowCompetition" treatment, lenders have little to lose and lots to gain from sharing information, and we therefore expect full information sharing (2 lenders per region). The opposite case is the "LowMobilityHighCompetition" treatment, where lenders have lots to lose and little to gain from sharing information. Here we expect that lenders will never share information with their competitors, so that only partial information sharing takes place (1 lender per region). Comparing the outcome of the "HighMobility-LowCompetition" to that of the "LowMobility-HighCompetition" treatment we should therefore find a substantial joint

\footnotetext{
${ }^{9}$ Note that our predictions are not affected if we assume that lenders make completely simultaneous decisions, i.e., joining decision are not only made simultaneously across regions but also within regions. The only difference is the following: With completely simultaneous decisions with respect to information sharing it is not determined which of the two lenders in a region joins the credit bureau in a partial sharing equilibrium. If the decision to join is taken sequentially within each region, then the first-mover will join the credit bureau and the second-mover will not, i.e., simultaneous decisions within regions create a coordination problem for the lenders in a region, but do not affect individual incentives to join the credit bureau.
} 
impact of borrower mobility and lender competition on information sharing.

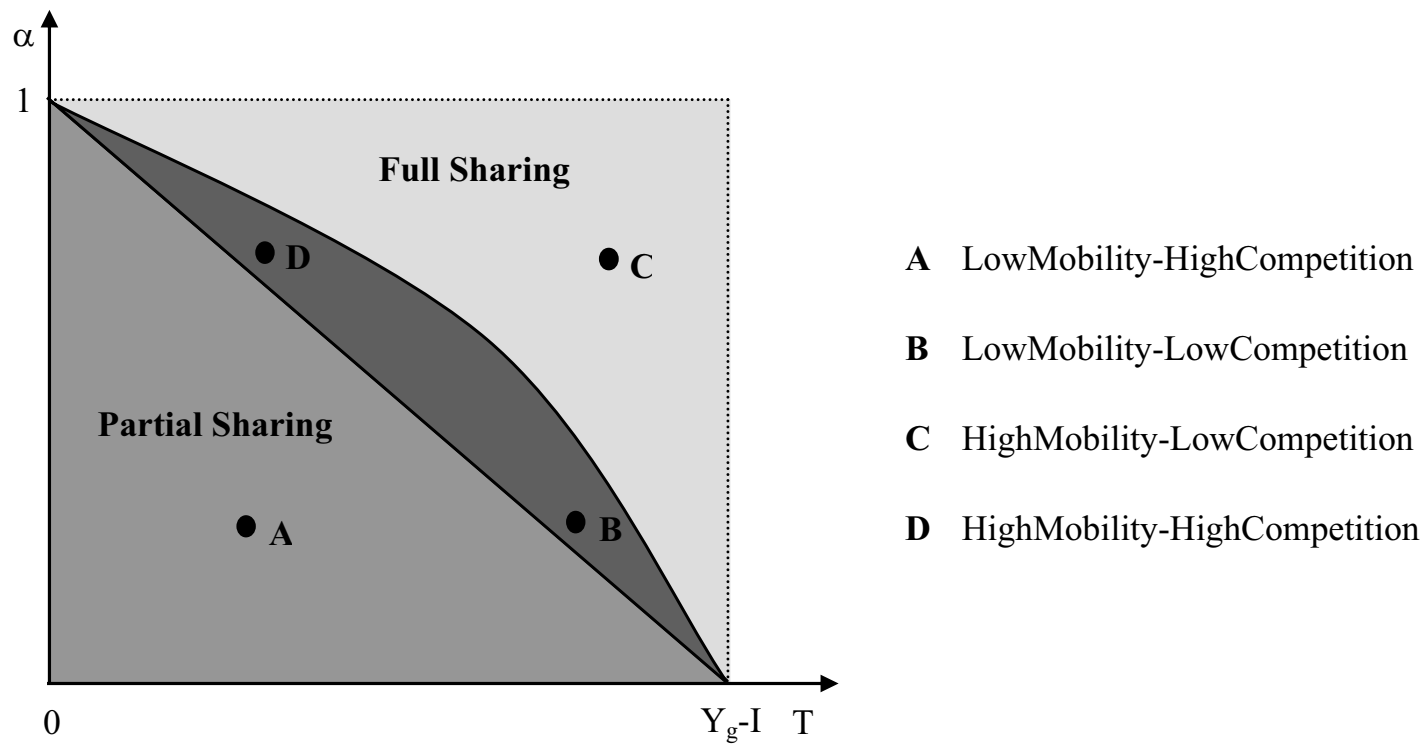

Figure 2: Market Equilibria

In the "HighMobility-HighCompetition" both full information sharing and partial sharing are feasible. The actual outcome of this treatment thus allows us to examine whether information sharing emerges when strong adverse selection makes it valuable, but strong lender competition reduces banks incentives to exchange information. By comparing the actual outcome of this treatment to our benchmark treatments we can establish and compare the individual impact of borrower mobility and lender competition on information sharing. Comparing the outcome of the "HighMobility-HighCompetition" treatment to that of the "HighMobility-LowCompetition" treatment will show us the individual impact of lender competition on information sharing. The comparison of the "HighMobility-HighCompetition" and "LowMobility-HighCompetition" treatments will show us the individual impact of borrower mobility on information sharing.

In the "LowMobility-LowCompetition" full information sharing and partial sharing are also feasible. The actual outcome of this treatment also allows us to establish and compare the individual impact of borrower mobility and lender competition on information sharing. Comparing the outcome of the "LowMobility-LowCompetition" treatment to that of the "LowMobility-HighCompetition" treatment gives us further evidence on the individual impact of lender competition on information sharing. The comparison of the "LowMobility-LowCompetition" and "HighMobility-LowCompetition" treatments yields additional evidence on the individual impact of borrower mobility on information sharing.

Our predictions are derived under the assumption of risk neutrality of lenders. In 
Appendix A.2 we investigate how risk aversion affects the feasibility of partial and full information sharing in our experiment. We show there that the presence of risk averse lenders enlarges (reduces) the set of parameter constellations for which full (partial) information sharing is feasible. This is intuitive, as full information sharing means that all lenders realize a safe payoff, while partial information sharing implies that lenders earn risky payoffs. However, it is rather unlikely that our participants are risk-averse enough to alter the equilibrium predictions for our four treatments. The treatment that is most likely to be affected is the "HighMobility-HighCompetition" treatment. If lenders are strongly risk-averse, partial sharing is no longer an equilibrium in this treatment. However, the degree of risk-aversion needed for this to be the case is implausibly high (see Observation A2 in Appendix A.2 for details). For example, a participant with such preferences would rather take a fixed payment of 108 points (CHF 0.72) instead of lottery where he would get 300 points (CHF 2.00) with probability 0.5 and zero otherwise (i.e., a risk premium of almost 30 percent in a decision with very low stakes). Thus, as long as the participants' preferences are not extreme, the presence of risk aversion does not affect our predictions.

\section{Results}

Table 2 presents summary statistics for information sharing, credit volume, and lenders' earnings for each of our four treatments. For each statistic the table presents the mean value across the 5 sessions of each treatment and the highest mean value (max) and lowest mean value (min) of an individual session.

\subsection{Information Sharing}

Our results show that adverse selection and lender competition systematically affect information sharing. We measure information sharing by the frequency with which lenders join the credit bureau. As expected, information sharing is most prevalent in the HighMobilityLowCompetition treatment, where $90 \%$ of lenders join the credit bureau. Information sharing is least frequent in the LowMobility-HighCompetition treatment, where only $47 \%$ of lenders join the bureau. The joint impact of borrower mobility and lender competition on information sharing is thus substantial in our experiment. A non-parametric test confirms that information sharing is significantly more frequent in the HighMobilityLowCompetition than in the LowMobility-HighCompetition treatment. ${ }^{10}$

\footnotetext{
${ }^{10}$ All 5 sessions of the HighMobility-LowCompetition treatment display more information sharing, than any of the 5 sessions of the LowMobility-HighCompetition treatment. A one-sided Mann-Whitney Test based on session averages therefore yields a coefficient of $p=.004$.
} 
Table 2: Summary Statistics

Panel A: Treatments with High Mobility

\begin{tabular}{lcccccc}
\hline \hline Treatment & \multicolumn{3}{c}{$\begin{array}{c}\text { HighMob-LowComp } \\
(\mathrm{a}=.75, \mathrm{~T}=160)\end{array}$} & \multicolumn{3}{c}{ HighMob-HighComp } \\
& mean & max & min & mean & max & min \\
Information sharing & 0.90 & 0.96 & 0.82 & 0.86 & 0.91 & 0.78 \\
& & & & & & \\
Loans & 0.95 & 0.98 & 0.91 & 0.98 & 1.03 & 0.93 \\
Good loans & 0.92 & 0.96 & 0.85 & 0.90 & 0.93 & 0.88 \\
Bad loans & 0.03 & 0.06 & 0.00 & 0.07 & 0.14 & 0.03 \\
Repayments "competition" & 237 & 250 & 218 & 175 & 179 & 171 \\
Repayments "monopoly" & 288 & 298 & 275 & 282 & 290 & 270 \\
& & & & & & \\
Profits & 289 & 304 & 268 & 266 & 277 & 256 \\
\hline
\end{tabular}

Panel B: Treatments with Low Mobility

\begin{tabular}{lcccccc}
\hline \hline Treatment & \multicolumn{3}{c}{$\begin{array}{c}\text { LowMob-LowComp } \\
(\mathrm{a}=.25, \mathrm{~T}=160)\end{array}$} & \multicolumn{3}{c}{$\begin{array}{c}\text { LowMob-HighComp } \\
\end{array}$} \\
& mean & max & min & mean & max & min \\
Information sharing & 0.56 & 0.60 & 0.50 & 0.47 & 0.52 & 0.43 \\
& & & & & & \\
Loans & 0.91 & 0.98 & 0.89 & 0.93 & 0.97 & 0.88 \\
Good loans & 0.87 & 0.93 & 0.85 & 0.87 & 0.93 & 0.81 \\
Bad loans & 0.04 & 0.05 & 0.01 & 0.06 & 0.10 & 0.03 \\
Repayments "competition" & 233 & 245 & 215 & 180 & 188 & 173 \\
Repayments "monopoly" & 296 & 298 & 290 & 294 & 297 & 289 \\
& & & & & & \\
Profits & 330 & 333 & 328 & 340 & 350 & 331 \\
\hline
\end{tabular}

Notes: The table presents summary statistics by treatment. For each statistic the table presents the mean value across the 5 sessions of each treatment and the highest mean value ( $\max$ ) and lowest mean value ( $\mathrm{min})$ of an individual session. Information sharing is the frequency with which lenders join the credit bureau. Loans is the number of loans extended per lender and period. Good loans is the number of loans extended per lender and period to an entrepreneur which the lender knows is good. Bad loans is the number of loans extended per lender and period to an entrepreneur which the lender knows is bad. Repayments "competition" is the repayments demanded by lenders in credit contracts sealed with good entrepreneurs if both lenders in the region know the entrepreneur is good. Repayments "monopoly" is the repayments demanded by lenders in credit contracts sealed with good entrepreneurs if only this lender knows the entrepreneur is good. Profits is the period payoff of lenders. 
The outcome of the HighMobility-HighCompetition treatment suggests that the impact of borrower mobility on information sharing is substantially stronger than that of lender competition. The level of information sharing in this treatment is surprisingly high $(86 \%)$, given that due to strong lender competition, partial information sharing is also a feasible outcome. Comparing the HighMobility-HighCompetition to the LowMobilityHighCompetition treatment, we see that an increase in borrower mobility from $\alpha=.25$ to $\alpha=.75$ (while holding $T=60$ ) raises the frequency of information sharing from $47 \%$ to $86 \%{ }^{11}$ In contrast, the difference in information sharing between the HighMobilityHighCompetition treatment and the HighMobility-LowCompetition treatment is negligible. Increasing lender competition by reducing transaction costs from $T=160$ to $T=60$ decreases the frequency of information sharing only from $90 \%$ to $86 \%$, although our predictions suggest that it could also lead to partial information sharing (50\%). Non-parametric tests suggest that this difference is not significant. ${ }^{12}$

The outcome of the LowMobility-LowCompetition treatment confirms that borrower mobility has a stronger impact on information sharing in our experiment than lender competition. The level of information sharing in this treatment is only 56\%. Comparing the LowMobility-LowCompetition to the LowMobility-HighCompetition treatment, we see that increasing transaction costs from $T=60$ to $T=160$ (while holding borrower mobility at $\alpha=.25$ ) increases the frequency of information sharing only from $47 \%$ to $56 \%$, although our predictions suggest this change could lead to full information sharing. ${ }^{13}$ In contrast, comparing the LowMobility-LowCompetition to the HighMobilityLowCompetition treatment we see that the increase in borrower mobility from $\alpha=.25$ to $\alpha=.75$ (while holding $T=160$ ) raises the frequency of information sharing substantially from $56 \%$ to $90 \% .^{14}$

An analysis of information sharing at the regional level confirms that full information sharing is significantly more frequent in the "HighMobility-HighCompetition" treatment

\footnotetext{
${ }^{11}$ All 5 sessions of the HighMobility-HighCompetition treatment display more information sharing than any of the 5 sessions of the LowMobility-HighCompetition treatment. A one-sided Mann-Whitney Test based on session averages therefore confirms in both cases that information sharing is more prevalent under high borrower mobility $(p=.004)$.

${ }^{12}$ In the HighMobility-LowCompetition treatment the frequency of information sharing in the 5 sessions is $.82, .89, .90, .93, .96$ respectively. In the HighMobility-HighCompetition treatment the frequency of information sharing in the 5 sessions is $.78, .83, .87, .88, .91$ respectively. A one-sided Mann Whitney test based on session observations thus yields a coefficient of $p=.111$.

${ }^{13}$ In the LowMobility-LowCompetition treatment the frequency of information sharing in the 5 sessions is $.50, .55, .56, .60, .60$ respectively,. In the LowMobility-HighCompetition treatment the frequency of information sharing in the 5 sessions is $.43, .44, .48, .49, .52$ respectively. A one-sided Mann Whitney test based on session observations thus yields a coefficient of $p=.008$.

${ }^{14}$ All 5 sessions of the HighMobility-LowCompetition treatment display more information sharing than any of the 5 sessions of the LowMobility-LowCompetition treatment. A one-sided Mann-Whitney Test based on session averages therefore confirms in both cases that information sharing is more prevalent under high borrower mobility $(p=.004)$.
} 
than in the "LowMobility-LowCompetition" treatment. Figure 3 displays, by treatment, the frequency with which both lenders, 1 lender, or no lender in a region join the credit bureau per region. ${ }^{15}$ The figure shows that in the "HighMobility-HighCompetition" treatment full sharing of information (2 lenders per region) is the most frequent outcome, occurring $72 \%$ of the time. This is only slightly lower than in the "HighMobilityHighCompetition" treatment, where two lenders per region join the credit bureau in $82 \%$ of the cases. In stark contrast, we find that partial information sharing ( 1 lender per region) is the dominant outcome in the "LowMobility-LowCompetition" treatment. In this treatment, both lenders of a region join the credit bureau $24 \%$ of the time, while only one lender joins $64 \%$ of the time. Full information sharing in this treatment is thus only slightly more common than in the "LowMobility-HighCompetition" treatment, where two lenders of the same region join the bureau $14 \%$ of the time.

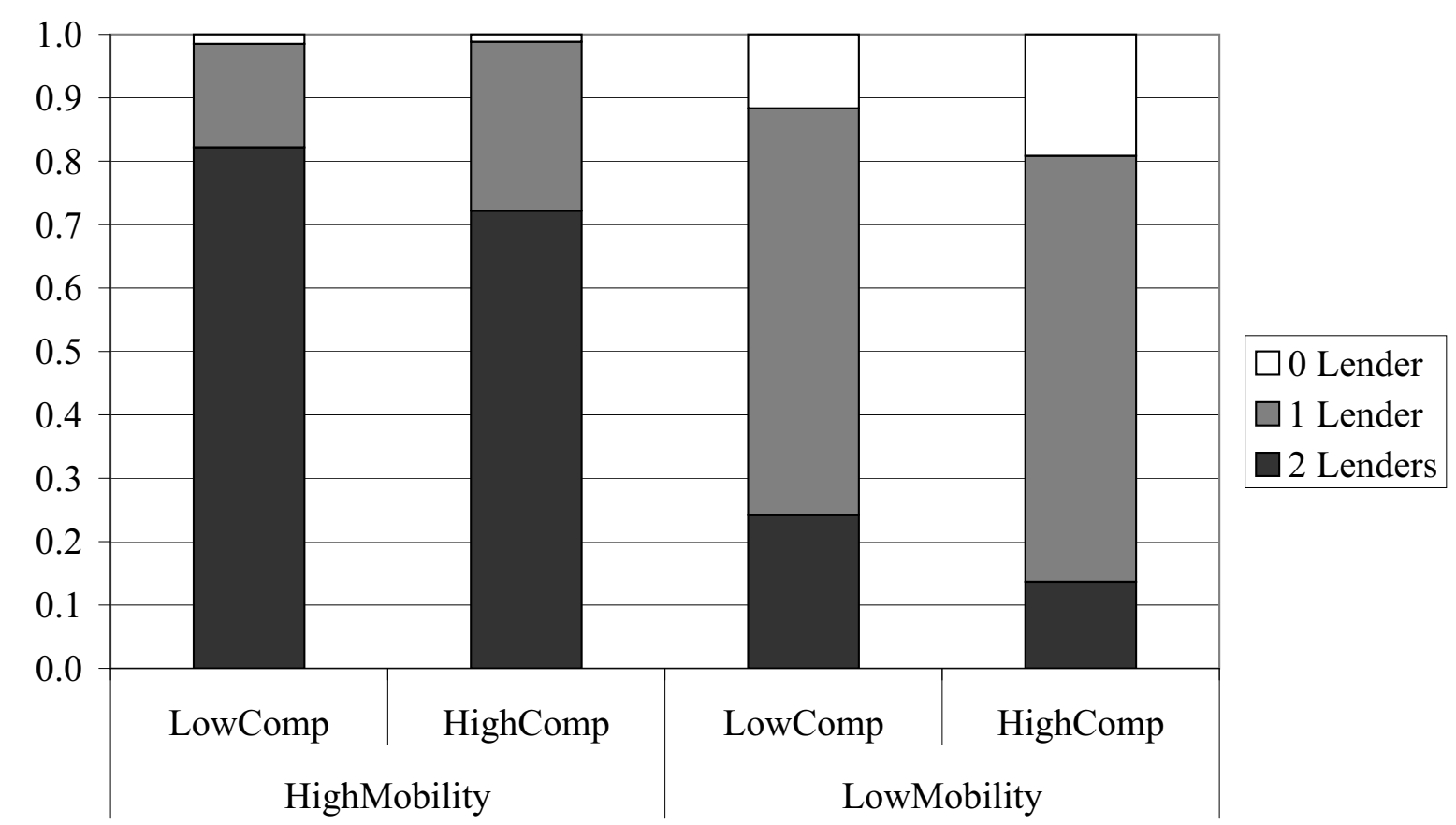

Figure 3: Frequency of Credit Bureau Participation

Why is the frequency of full information sharing substantially higher in the "HighMobility-HighCompetition" than in the "LowMobility-LowCompetition" treatment? Our predictions suggest that the driving force behind this result are lenders' beliefs about the information sharing behavior of other lenders. In both treatments it is payoff-maximizing for the two lenders in region A to join the credit bureau, if they expect

\footnotetext{
${ }^{15}$ In each treatment $n=600$. For each treatment we conducted 5 sessions of 20 periods each. In each period of each session there are 2 regions in each of the 3 markets.
} 
that the two non-competing lenders in region $\mathrm{B}$ also join. If, however, they believe that only one non-competitor from region $\mathrm{B}$ joins the credit bureau, then the best response of the second lender in region A is not to join the credit bureau. According to our theory, therefore, full information sharing may emerge in the "HighMobility-HighCompetition" because in this treatment second-mover lenders coordinate on full sharing of information. In contrast, it seems that in the "LowMobility-LowCompetition" treatment second-mover lenders coordinate on partial information sharing. If "coordination" explains differences in information sharing between the "HighMobility-HighCompetition" and the "LowMobilityLowCompetition" treatment we should find that, in both treatments, lenders' beliefs about information sharing of other lenders affect their decision to join the credit bureau. We examine whether this is the case by carrying out a regression analysis of decisions to join the credit bureau. We relate individual decisions to the lender's belief about how many other lenders will join the credit bureau. We did not elicit lenders' beliefs explicitly in our experiment. However, we argue that a lender will expect more non-competitors to join if in the past he or she observed a high rate of participation in the credit bureau. As an indicator of lenders' beliefs concerning other lenders information sharing behavior we therefore take the share of non-competing lenders who joined the credit bureau in all past markets the lender was involved in. This indicator, which we label "Past information sharing", varies substantially across lenders in each treatment and also varies over time for all lenders. In the "HighMobility-HighCompetition" treatment the average value of "Past information sharing" is .85 both in period 2 and period 20, while individual lender values are in the range $[0,1]$ in period 2 , and in the range $[.74, .96]$ in period 20 . In the "LowMobility-LowCompetition" treatment the average value of "Past information sharing" is .58 in period 2 and .56 in period 20, while individual lender values are in the range $[0,1]$ in period 2 , and in the range $[.37, .72]$ in period 20 .

Table 3 reports our estimation results, with columns (1) and (2) displaying results for the "HighMobility-HighCompetition" treatment, while columns (3) and (4) display results for the "LowMobility-LowCompetition" treatment. Columns (1) and (3) report the results, when we pool the information sharing decisions of first-mover and secondmover lenders. The coefficients displayed are marginal effects of probit estimations, with standard errors adjusted for clustering at session level. In order to control for time effects, not related to changes in lenders' beliefs, we control for the period in which a decision takes place. The positive coefficient of "Past information sharing" in column (1) suggests that beliefs about information sharing of other lenders does affect credit bureau participation in the "HighMobility-HighCompetition" treatment. In this treatment, lenders who experienced high credit bureau participation of other lenders in the past are more likely to share information. 
Table 3: Individual Probability of Information Sharing

\begin{tabular}{lcccc}
\hline \hline Treatment: & \multicolumn{2}{c}{ HighMob-HighComp } & \multicolumn{2}{c}{ LowMob-LowComp } \\
Lenders: & All & 2nd movers & All & 2nd movers \\
\hline Past information sharing & 0.27 & 0.327 & -0.348 & -0.204 \\
& {$[1.96]^{* *}$} & {$[1.67]^{*}$} & {$[2.97]^{* * *}$} & {$[1.07]$} \\
First-mover joined & & -0.104 & & -0.309 \\
& & {$[1.62]$} & & {$[5.63]^{* * *}$} \\
Period & 0 & -0.001 & -0.003 & -0.006 \\
& {$[0.05]$} & {$[0.22]$} & {$[1.85]^{*}$} & {$[2.05]^{* *}$} \\
\hline Observations & 1140 & 570 & 1140 & 570 \\
\hline
\end{tabular}

Notes: The table reports regression estimates using individual data on credit bureau participation in the "HighMobility-HighCompetition" and "LowMobility-LowCompetition" treatments. All columns report probit estimates for the probability of a lender joining the credit bureau. Columns (1) and (3) use data of first and second-mover lenders for the "HighMobility-HighCompetition" and "LowMobility-LowCompetition" treatments. Columns (2) and (4) use data of second-mover lenders only for the "HighMobility-HighCompetition" and "LowMobility-LowCompetition" treatments. The regressions use include the following explanatory variables: Past information sharing is the share of non-competing lenders who joined the credit bureau in markets a lender participated in previous periods. Period is the period in which the decision to join the credit bureau is made. First mover joined (for columns (2) and (4) only) is a dummy variable which is one if the first-mover in the lender's region has decided to join the credit bureau. In all regressions the T-statistics reported in parentheses are based on standard errors adjusted for clustering at session level. ${ }^{*}$ indicates significance at the 5 percent level; ${ }^{* *}$ indicates significance at the 1 percent level.

Column (3) shows a contrasting result for the "LowMobility-LowCompetition" treatment. In this treatment the coefficient of "Past information sharing" is negative, suggesting that lenders who experienced high credit bureau participation in the past are less likely to join the credit bureau. This result is puzzling. It may, however, be explained by the fact that our analysis includes both first-mover and second-mover decisions. If a first-mover expects low credit bureau participation from non-competitors, but thinks that the second-mover in his region (due to high past credit bureau participation) expects both competitors to join, then it is rational for the first-mover to stay out of the bureau. In order to rule out this effect we repeat our analysis for second-movers only. Columns (2) and (4) display the corresponding estimated coefficients for the "HighMobility-HighCompetition" and the "LowMobility-LowCompetition" treatments. When analyzing second-mover behavior, we control for the (observed) decision of the first-mover in that region, as this should reduce incentives of second-movers to share information. Column (4) reveals that there is no significant impact of "Past information sharing" on credit bureau participation of second-movers in the "LowMobility-LowCompetition" treatment. Column (2), meanwhile, confirms our earlier result, that information sharing in the "HighMobility- 
HighCompetition" treatment is positively related to past credit bureau participation. As expected, information sharing of second-movers is lower in both treatments if the firstmover of the region joins the credit bureau.

The analysis displayed in Table 3 suggests that lenders do "coordinate" on full information sharing in the "HighMobility-HighCompetition" treatment. Initial credit bureau participation in this treatment is high. Moreover, lenders who experience full information sharing in earlier periods believe that this will continue in future and thus join the credit bureau in following periods. Information sharing behavior in the "LowMobilityLowCompetition" treatment seems to be completely different. Here, credit bureau participation is low in early periods. Moreover, in this treatment, second-mover lenders who experience high levels of information sharing are not more likely to join the credit bureau in following periods. These findings suggest that expectations in this treatment are strongly anchored at partial information sharing.

\subsection{Credit and Profits}

Lenders' earnings in our experiment are significantly affected by information sharing. The summary statistics in table 2 display the mean repayments received by lenders on loans to good borrowers. The table shows that a lender's earnings from extending credit to a good borrower depend strongly on whether the competing lender in the same region also knows that the borrower was good. If only one lender in a region knows that a particular borrower is good, then this lender should earn a monopoly profit. By design, the maximum repayment lenders can demand from borrowers is 300 (this was the certain investment earning of good borrowers). In all four treatments, good borrowers must make repayments close to 300, if only one lender can identify their type. If, in contrast, both lenders in a region can identify a good borrower, competition drives repayment demands down. The lowest repayment which the lender in the same sector as the borrower can demand (and make non-negative profits) is the cost of funds, 100. Due to transaction costs $T$ of lending across sector borders, the lowest repayment which the lender in the other sector of the region can demand (and make non-negative profits) is $100+T$. If both lenders can identify the same good borrower, competition should thus lower repayment demands to $100+T$. In the "High Competition" treatments $(T=60)$ this implies a level of 160 , while in the "Low Competition" treatments $(T=160)$ it implies a repayment level of 260 . Table 2 shows indeed that repayments paid by good borrowers are close to these competitive levels, when both lenders in a region can identify a good borrower.

Repayment levels suggest that when lenders share information in our experiment, they do create substantial endogenous competition for good borrowers. This should imply that lenders earn lower profits in treatments with more information sharing. Our summary 
statistics confirm that this is the case. While lenders in high-mobility treatments extend similar credit to those in low-mobility treatments, they do earn substantially less from these loans. On average, lenders earn 41 points more per period in the "LowMobilityLowCompetition" treatment than in the "HighMobility-LowCompetition" treatment. Further, lenders earn 74 points more per period in the "LowMobility-HighCompetition" treatment than in the "HighMobility-HighCompetition" treatment. Non-parametric tests confirm that these differences are statistically significant in both comparisons. ${ }^{16}$

Finally, table 2 shows that the volume and quality of lending in our experiment is hardly affected by borrower mobility or lender competition. On average, each lender extends roughly 1 loan per period in all treatments. The number of loans varies slightly across treatments, but non-parametric tests suggest that differences between treatments are insignificant. ${ }^{17}$ The quality of lending is extremely high in all treatments. The vast majority of loans are made to good borrowers, while loans to bad borrowers are rare. Remembering that there are an equal number of lenders and good borrowers in our credit market, these results suggest that, in all treatments, lenders managed to extend credit to most good borrowers, while avoiding loans to the more frequent bad borrowers. Lenders were thus able to overcome information asymmetries which arise from borrower mobility. This finding suggests that the higher level of information sharing in the high-mobility treatments enabled lenders to fully overcome the higher degree of asymmetric information in these treatments.

\section{Conclusions}

We examine how adverse selection and competition in the credit market affect voluntary information sharing between lenders. Our experimental results confirm that lenders are more likely to engage in information sharing when they face strong information asym-

\footnotetext{
${ }^{16}$ All 5 sessions of the "HighMobility-LowCompetition" treatment display lower per period lender profits than any of the 5 sessions of the "LowMobility-LowCompetition" treatment. Likewise, all 5 sessions of the "HighMobility-HighCompetition" treatment display lower lender profits than any of the 5 sessions of the "LowMobility-HighCompetition" treatment. A one-sided Mann-Whitney Test based on session averages therefore confirms in both cases that information sharing is more prevalent under high borrower mobility $(\mathrm{p}=.004)$.

${ }^{17}$ In the "HighMobility-LowCompetition" treatment the average number of loans per period and lender is $.91, .95, .95, .96, .98$ respectively. In the "HighMobility-HighCompetition" treatment this is $.93, .94, .99, .99,1.03$ respectively. In the "LowMobility-LowCompetition" treatment this is $.89, .90, .90, .90, .98$ respectively. In the "LowMobility-HighCompetition" treatment this is $.88, .90, .93, .96, .97$ respectively. Two-sided Mann Whitney tests based on session observations thus yield coefficients of $\mathrm{p}=.42$ ("HighMobility-LowCompetition" versus "HighMobility-HighCompetition"), p=.546 ("LowMobility-LowCompetition" versus "LowMobilityHighCompetition"), $\mathrm{p}=.15$ ("HighMobility-LowCompetition" versus "LowMobility-LowCompetition"), and $\mathrm{p}=.15$ ("HighMobility-HighCompetition" versus "LowMobility-HighCompetition").
} 
metries. Lenders are less likely to share information when credit market competition is intense. Our results further suggest that the impact of adverse selection on information sharing is much stronger than that of lender competition.

Our findings may explain a puzzling development in credit markets over the past two decades: Voluntary information sharing through private credit bureaus has grown most rapidly in the consumer credit market, despite the fact that this market is highly competitive in most countries. Our results suggest that information sharing may be high in the consumer credit market despite strong competition, because due to borrower mobility etc. this market segment is subject to substantial information asymmetries. Under these circumstances, our findings suggest that potential adverse selection may drive information sharing behavior, while lender competition may only be of minor importance. 


\section{References}

Barron, J. M. and M. Staten (2003): "The Value of Comprehensive Credit Reports: Lessons from the U.S. Experience", in M.J. Miller (ed.), Credit Reporting Systems and the International Economy, Boston: MIT Press.

Bouckaert, J. and H. Degryse (2006): "Entry and Strategic Information Display in Credit Markets", Economic Journal, 116, 702-720.

Brown, M. and C. Zehnder (forthcoming): "Credit Reporting, Relationship Banking, and Loan Repayment", Journal of Money, Credit, and Banking.

Brown, M. and T. Jappelli, and M. Pagano (2007): "Information Sharing and Credit: Firm-Level Evidence from Transition Countries", CEPR Discussion Paper No. 6313.

Degryse, H. and S. Ongena (2005): "Distance, lending relationships, and Competition", The Journal of Finance, 60 , 231-266.

Djankov, S., C. McLiesh and A. Shleifer (2007): "Private Credit in 129 Countries", Journal of Financial Economics, 84, 299-329.

Fischbacher, U. (2007): "z-Tree: Zurich Toolbox for Readymade Economic Experiments", Experimental Economics, 10, 171-178.

Galindo, A. and M. J. Miller (2001): "Can Credit Registries Reduce Credit Constraints? Empirical Evidence on the Role of Credit Registries in Firm Investment Decisions", Paper prepared for the Annual Meetings of the Inter-American Development Bank, Santiago Chile.

Hunt R. (2005): "A Century of Consumer Credit Reporting in America", Federal Reserve Bank of Philadelphia Working Paper 05-13.

Jappelli, T. and M. Pagano (2002): "Information Sharing, Lending and Defaults: CrossCountry Evidence", Journal of Banking \& Finance, 26, 2017-2045.

Kallberg, J. G., and G. F. Udell (2003): "The Value of Private Sector Credit Information", Journal of Banking \& Finance, 27, 449-469.

Klein, D. B. (1992): "Promise Keeping in the Great Society: A Model of Credit Information Sharing", Economics and Politics, Vol.4(2), 117-136.

Love I., and N. Mylenko (2003): "Credit Reporting and Financing Constraints" , World Bank Policy Research Working Paper 3142. 
Luoto, J., C. McIntosh, and B. Wydick (2007): "Credit Information Systems in LessDeveloped Countries: A Test with Microfinance in Guatamala", Economic Development and Cultural Change, 55, 313-334.

Olegario R. (2003): "Credit Reporting Agencies", in M.J. Miller (ed.), Credit Reporting Systems and the International Economy, Boston: MIT Press.

Padilla, A. J. and M. Pagano (2000): "Sharing Default Information as a Borrower Discipline Device", European Economic Review 44 (10), 1951-1980.

Pagano, M. and T. Jappelli (1993): "Information Sharing in Credit Markets", The Journal of Finance, 43(5), 1693-1718.

Powell, A., N. Mylenko, M. Miller, and G. Majnoni (2004): "Improving Credit Information, Bank Regulation and Supervision: On the Role and Design of Public Credit Registries, World Bank Policy Research Working Paper 3443.

San José Riestra, A. (2002): "Credit Bureaus in Today's Credit Markets", ECRI Research Report 4/2002.

Selten, R. (1975): "A Reexamination of the Perfectness Concept for Equilibrium Points in Extensive Games", International Journal of Game Theory, 4, 25-55.

Vercammen, J. A. (1995), "Credit Bureau Policy and Sustainable Reputation Effects in Credit Markets", Economica, 62, 461-478. 


\section{Appendix}

\section{A Mathematical Appendix}

\section{A.1 Proof of Lemma 1}

Proof. Consider first the decision of a second-mover lender, given that the first-mover lender in the same region does not join the credit bureau:

- If the lender does not join the credit bureau and the entrepreneurs do not switch regions, he will conclude a credit contract with the good entrepreneur in his home market, thus earning a payoff of $\pi^{L}=\left(Y_{g}-I\right)$. If the entrepreneurs do switch regions and the lender is not a member of the credit bureau, he has no information on any entrepreneurs situated in his region and will thus not lend. As entrepreneurs switch with probability $\alpha$, the expected payoff from not joining is $E \pi^{L}=(1-\alpha)\left(Y_{g}-I\right)$.

- If the lender does join and entrepreneurs do not switch, he still earns $\pi^{L}=\left(Y_{g}-I\right)$ as his competitor has no information on the entrepreneurs in the lender's sector. If the lender joins and entrepreneurs do switch, he earns zero profits if neither of the two lenders in the other region of the credit market has joined. The problem is that, in this case, the lender has no information on any entrepreneurs situated in his region and will thus not lend. If entrepreneurs switch and one of the two lenders in the other region also joins, then he has information about the entrepreneurs coming from the other bureau member and can conclude credit contracts with the good types. Joining therefore results, for the lender, in either a payoff of $\pi^{L}=\left(Y_{g}-I\right)$ or $\pi^{L}=\left(Y_{g}-I-T\right)$, depending on the sector to which the known borrowers from the other region move. The expected payoff of the lender from joining, given that one other lender in the other region joins, is $E \pi^{L}=\frac{1}{2}\left(\left(Y_{g}-I\right)+\left(Y_{g}-I-T\right)\right)$. If entrepreneurs switch and both lenders in the other region of the credit market join, then the lender knows all good entrepreneurs who come to his region and his payoff from joining is given by $\pi^{L}=\left(Y_{g}-I\right)+\left(Y_{g}-I-T\right)$. Thus, the lender's expected payoff from joining depends on the behavior of the lenders in the other region. However, summarizing we can say that the lenders expected payoff can be characterized by the following expression, $(1-\alpha)\left(Y_{g}-I\right)+\alpha \gamma\left(Y_{g}-I+Y_{g}-I-T\right)$, where $\gamma \in\{0 ; 0.5 ; 1\}$ is the fraction of joining lenders in the other region.

If a the first-mover lender does not join the credit bureau, then the second-mover lender is indifferent between joining and not joining, if both lenders in the other region do not join. But, if either one or both of the lenders in the other region join, then the lender is strictly better off by joining.

Now consider the decision of a second-mover lender, given that the first-mover lender in the same region does join the credit bureau:

- If the lender does not join the credit bureau he will, as above, earn a payoff of $\pi^{L}=\left(Y_{g}-I\right)$ with the probability $(1-\alpha)$. 
- If the lender does join and entrepreneurs do not switch he will now only earn a payoff of $\pi^{L}=T$, as his competitor also has information on the entrepreneurs in the lender's sector. If the lender does join and entrepreneurs switch, then the following outcomes are possible: The lender earns a payoff of 0 if neither of the two lenders in the other region has joined and the lender therefore does not have information on any of the borrowers in his region. If one of the two lenders in the other region joins, then the lender earns either a payoff of $\pi^{L}=T$, if the known entrepreneurs from the other region move to the lender's sector, or $\pi^{L}=0$, if the known entrepreneurs from the other region move to the competitor's sector. As both outcomes are equally likely the lender's expected profit in the event that only one lender in the other region joins is $E \pi^{L}=\frac{1}{2} T$. If both lenders in the other region join, then the lender's payoff is given by $\pi^{L}=T$, as he can conclude a credit contract with the good entrepreneur who moves to his sector. Summarizing, we can therefore state the lender's expected profit from joining as $E \pi^{L}=(1-\alpha) T+\alpha \gamma T$, where $\gamma \in\{0 ; 0.5 ; 1\}$ is the fraction of lenders in the other region who join.

If the first-mover lender does join the credit bureau it is therefore a best response for the second-mover lender to join if and only if $(1-\alpha+\alpha \gamma) T>(1-\alpha)\left(Y_{g}-I\right)$.

\section{A.2 Predictions with risk-averse lenders}

In this section we analyze the impact of risk aversion on the lenders' decisions to join the credit bureau:

Lemma A1. (second-mover behavior with risk aversion) i) If the first-mover lender in a region does not join the credit bureau, the second-mover lender is strictly better off by joining if at least one non-competing lender also joins. If no other lender joins, then the second-mover lender is indifferent between joining and not. ii) If the first-mover lender in a region does join the credit bureau, then the second-mover lender is better off by joining only if $(1-\alpha)\left(Y_{g}-I\right)-\frac{1}{2} r \alpha(1-$ $\alpha)\left(Y_{g}-I\right)^{2} \leq(1-\alpha+\gamma \alpha) T-\frac{1}{2} r(1-\gamma) \alpha(1-(1-\gamma) \alpha) T^{2}$, where $r$ is the coefficient of absolute risk aversion and $\gamma \in\{0 ; 0.5 ; 1\}$ is the share of non-competing lenders from the other region that join.

Proof. Consider first the decision of a risk-averse second-mover lender, given that the first-mover lender in the same region does not join the credit bureau:

- From the Proof of Lemma 1 above we know that the expected payoff from not joining is $E \pi^{L}=(1-\alpha)\left(Y_{g}-I\right)$, while the expected payoff from joining is $(1-\alpha)\left(Y_{g}-I\right)+$ $\alpha \gamma\left(Y_{g}-I+Y_{g}-I-T\right)$. Since $Y_{g}-I-T>0$ any monotonically increasing utility function $u(\cdot)$ implies that the second-mover lender is indifferent if $\gamma=0$ and strictly better off by joining if $\gamma \in\{0.5 ; 1\}$.

Now consider the decision of a risk-averse second-mover lender, given that the first-mover lender in the same region does join the credit bureau. In order to compare utilities from joining and not joining we apply the result of decision theory that a risk averse decision maker's certainty equivalent $(C E)$ for a random income with expected value $\bar{X}$ and Variance $V(X)$ can be approximated as $C E=\bar{X}-\frac{1}{2} r(\bar{X}) V(X)$, where $r$ is the coefficient of absolute risk aversion. For simplicity we assume that $r$ is constant and identical for all lenders. 
- If the second-mover lender does not join the credit bureau he earns a payoff of $\pi^{L}=\left(Y_{g}-I\right)$ with the probability $(1-\alpha)$. Accordingly, his certainty equivalent for this choice is given by: $C E=(1-\alpha)\left(Y_{g}-I\right)-\frac{1}{2} r \alpha(1-\alpha)\left(Y_{g}-I\right)^{2}$.

- If the second-mover lender joins the credit bureau, his expected payoff depends on the fraction of lenders in the other region who join $\gamma: E \pi^{L}=(1-\alpha) T+\alpha \gamma T$. We can write the certainty equivalent as a function of $\gamma$ in the following way: $(1-\alpha+\gamma \alpha) T-\frac{1}{2} r(1-$ $\gamma) \alpha(1-(1-\gamma) \alpha) T^{2}$.

If the first-mover lender does join the credit bureau it is therefore a best response for the secondmover lender to join if and only if $(1-\alpha)\left(Y_{g}-I\right)-\frac{1}{2} r \alpha(1-\alpha)\left(Y_{g}-I\right)^{2} \leq(1-\alpha+\gamma \alpha) T-$ $\frac{1}{2} r(1-\gamma) \alpha(1-(1-\gamma) \alpha) T^{2}$.

Lemma A2. (first-mover behavior with risk aversion) i) The first-mover lender in a region is strictly better off by joining the credit bureau if at least one non-competing lender also joins. ii) If no non-competing lender joins, the first-mover lender is indifferent between joining and not.

Proof. The sequence of arguments is identical to that for the Proof of Lemma 2.

Proposition A1. If lenders are risk-averse, there exists a Nash equilibrium in which all lenders join the credit bureau with certainty if and only if $(1-\alpha)\left(Y_{g}-I\right)-\frac{1}{2} r \alpha(1-\alpha)\left(Y_{g}-I\right)^{2} \leq T$.

Proof. The sequence of arguments is identical to that for the Proof of Proposition 1.

Proposition A2. If lenders are risk-averse, there exists a Nash equilibrium in which only the first-mover lender per region joins the credit bureau if and only if $(1-\alpha)\left(Y_{g}-I\right)-\frac{1}{2} r \alpha(1-$ $\alpha)\left(Y_{g}-I\right)^{2}>\left(1-\frac{1}{2} \alpha\right) T-\frac{1}{2} r \frac{1}{2} \alpha\left(1-\frac{1}{2} \alpha\right) T^{2}$.

Proof. The sequence of arguments is identical to that for the Proof of Proposition 2.

Observation A1. i) The set of parameter constellations for which full information sharing is feasible in equilibrium becomes larger when lenders are more risk-averse. Specifically, for a given degree of borrower mobility $\alpha \in(0,1)$ full information sharing is feasible under stronger competition if lenders are more risk-averse. ii) The set of parameter constellations for which partial information sharing is feasible in equilibrium becomes smaller when lenders are more risk-averse. Specifically, for a given degree of borrower mobility $\alpha \in(0,1)$ the feasibility of partial information sharing requires stronger competition if lenders are more risk-averse.

(For a graphical representation of Observation A1 see Figure A1.)

Proof. Consider first the condition for the feasibility of full information sharing in Proposition A1:

- Proposition A1 defines the minimal costs of inter-sectoral lending $T$ for each degree of borrower mobility $\alpha$, such that full information sharing can be sustained in equilibrium: $T \geq(1-\alpha)\left(Y_{g}-I\right)-\frac{1}{2} r \alpha(1-\alpha)\left(Y_{g}-I\right)^{2}$. The fact that $T$ is decreasing in $r$ whenever $\alpha \in(0,1)$ implies that full information sharing is feasible under stronger competition if lenders are more risk-averse.

Consider now the condition for the feasibility of partial information sharing in Proposition A2: 
- In a first step we show that there are parameter constellations, which satisfy the feasibility condition for partial information sharing under risk neutrality but not under risk aversion. To this end, define $T^{u}$ as the upper bound of $T$ for the feasibility of partial information sharing under risk neutrality $(r=0)$ for a given $\alpha: T^{u}=\frac{(1-\alpha)\left(Y_{g}-I\right)}{1-\frac{1}{2} \alpha}$. It is straightforward to see that $T^{u}$ only satisfies the condition for the feasibility of partial information sharing under risk aversion $(r>0)$ if $\alpha$ is either equal to 0 or equal to 1 . If $\alpha \in(0,1)$, a positive $r$ has a negative impact on both sides of the feasibility condition, but the absolute size of the effect is larger for the left-hand side of the condition. To show this we insert $T^{u}$ on both sides of the condition. Rearranging and canceling terms yields: $|-1|>\left|-\frac{1-\alpha}{2\left(1-\frac{1}{2} \alpha\right)}\right|$. As a consequence $T^{u}$ violates the condition whenever $r>0$ and $\alpha \in(0,1)$.

- In a second step we argue that for any $\alpha \in(0,1) T^{u}$ violates the feasibility condition for partial information sharing more strongly when lenders are more risk averse (i.e., the difference between the left-hand side and the right-hand side of the condition is increasing in $r$ ). This is due to the fact that both sides of the condition decrease linearly in $r$, but the negative impact is stronger on the left-hand side of the condition for any positive $r$ (see step 1 above).

- In a third step we proof that in order to satisfy the feasibility condition for partial information sharing, $T$ must be lower than $T^{u}$ if $\alpha \in(0,1)$ and lenders are risk averse $(r>0)$. For this to be the case we need to show that the derivative of the right-hand side of the condition with respect to $r$ is negative. It is straightforward to verify that this is satisfied for all $r<\frac{2}{\alpha T}$. However, in order for the approximation of the certainty equivalents to be reasonable this condition must be satisfied anyway (the certainty equivalent on the lefthand side of the feasibility condition is only positive as long as $\left.r<\frac{2}{\alpha\left(Y_{g}-I\right)}<\frac{2}{\alpha T}\right)$. Thus, the upper bound of $T$ for the feasibility of partial information sharing under risk aversion for a given $\alpha \in(0,1)$ must be strictly lower than $T^{u}$. Furthermore, step 2 implies that the upper bound is decreasing in $r$, which means that for a given $\alpha \in(0,1)$ the feasibility of partial information sharing requires stronger competition if lenders are more risk-averse.

Observation A2. Although the presence of risk averse lenders affects the set of parameter constellations for which multiple equilibria can be sustained, the predictions for our four treatments are only affected if lenders are highly risk averse. In order for the "HighMobilityHighCompetition" treatment ("LowMobility-LowCompetition" treatment) to drop from the set of constellations with multiple equilibria the coefficient of absolute risk aversion needs to be at least $r=0.47(r=0.53)$.

Proof. Solving the condition for the feasibility of partial information sharing (Proposition A2) for $r$ yields: $r<\frac{(1-\alpha)\left(Y_{g}-I\right)-\left(1-\frac{1}{2} \alpha\right) T}{\frac{1}{2}\left[\alpha(1-\alpha)\left(Y_{g}-I\right)^{2}-\frac{1}{2} \alpha\left(1-\frac{1}{2} \alpha\right) T^{2}\right]}$. Entering the parameter values of the experiment (converted to US- $\$$, i.e. 150 Points $=1$ Swiss Franc $=0.83$ US- $\$$ ) yields the reported numbers. 
Figure A1: Market Equilibria under Risk Neutrality and Risk Aversion

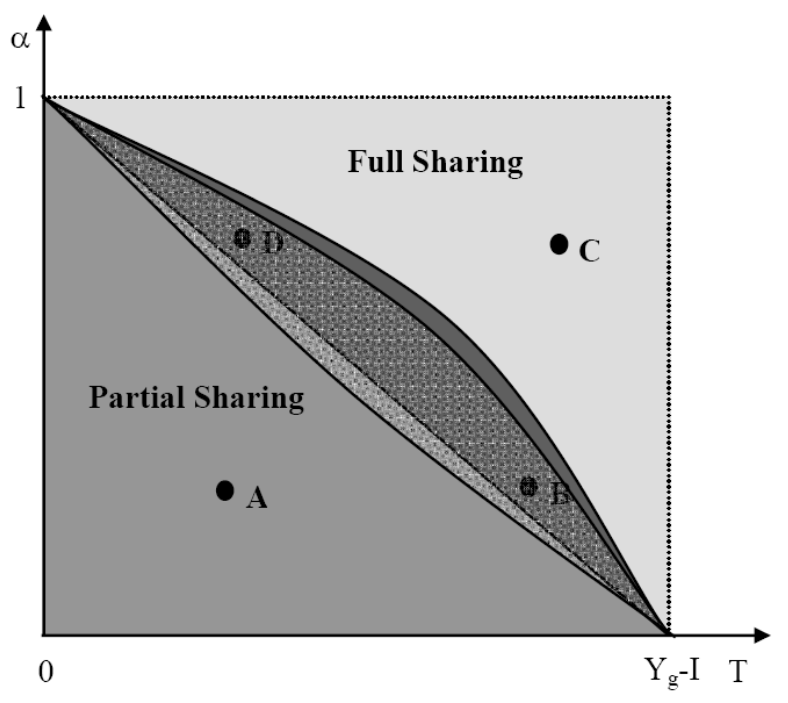

A LowMobility-HighCompetition
B LowMobility-LowCompetition
C HighMobility-HighCompetition
D HighMobility-LowCompetition

Multiple Equilibria under Risk Neutrality

Multiple Equilibria under Risk Aversion 


\section{Appendix B: Instructions}

The following instructions are a translation of the original German instructions for our "HighMobility-HighCompetition" treatment. In this treatment the mobility of entrepreneurs ("probability of changing location" in the instructions) is .75, and the costs of cross-sectoral lending ("transactions costs" in the instructions) are $\mathrm{T}=160$. The instructions for the other three treatments are identical, except that all references to "probability of changing location" and "transaction costs" bear the corresponding parameters of those treatments. The original instructions for all four treatments, as well as the z-Tree codes are available from the authors.

\section{Instructions}

You are about to participate in an economic experiment. Please read the following instructions carefully. These will provide you with all the necessary information for your participation in this experiment. If there is anything you do not understand, please raise your hand. We will then answer your question at your seat.

You will receive a show-up fee of 10 Swiss francs. You can earn a further sum of money during the experiment by gaining points.

The experiment is divided into 20 periods. You can earn points in each of these periods. The number of points you earn depends on your decisions and those of the other participants. All the points you earn during the 20 periods are converted to francs at the end of the experiment. The following exchange rate applies:

\section{0 points $=1$ franc}

At the end of the experiment you will immediately receive the sum of money that you earned plus your show-up fee in cash.

Please note that communication with the other participants is strictly prohibited during the entire experiment. We further advise you that you may only use those functions on the computer which are necessary for running the experiment. Communicating with other participants or playing around with the computer will lead to exclusion from the experiment. We are available to answer any questions you might have.

Twelve persons are participating in this experiment. You and all other participants are creditors for the entire duration of the experiment. 


\section{Short summary of the experiment procedures}

A total of 12 persons are participating in this experiment. There are three credit markets in each period with four persons each. In each period you will be assigned to a credit market with three other randomly chosen participants. A credit market consists of two regions, Region A and Region B. Each region is divided into two sectors; Region A consists of Sectors 1 and 2, and Region B consists of Sectors 3 and 4. There are one creditor (K) and four entrepreneurs (U) in each of the four sectors. ${ }^{1}$ You and the other three participants are the creditors. You will be randomly assigned to the role of a creditor ( $\mathrm{K} 1, \mathrm{~K} 2, \mathrm{~K} 3$ or $\mathrm{K} 4)$ in each period. The computer simulates the entrepreneurs.

Each creditor can extend credit to the entrepreneurs in his or her region, meaning that creditors $\mathrm{K} 1$ and $\mathrm{K} 2$ can grant credits to the entrepreneurs in the sectors 1 and 2, while creditors $\mathrm{K} 3$ and K4 can grant credits to the entrepreneurs in the sectors 3 and 4. The costs for granting credits depend on the sector in which the entrepreneur is. If the entrepreneur is in your own sector, the extension of credit involves no cost. If, however, the entrepreneur is in the other sector of your region, you must pay additional costs.

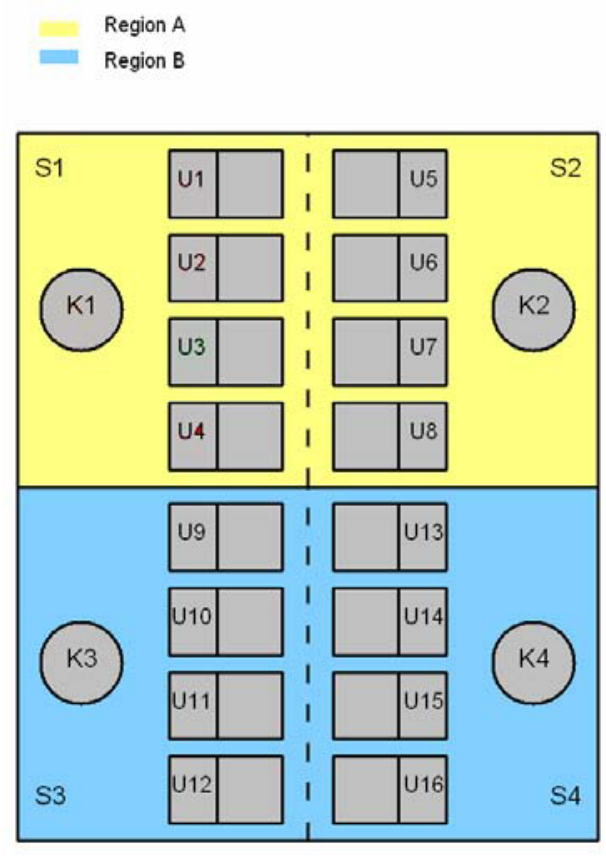

The entrepreneurs have no equity of their own and require a credit of 100 points each for the realization of a project. There are two types of entrepreneurs: "good" entrepreneurs and "bad" entrepreneurs. The good entrepreneurs' projects are always successful and yield an income of 300 points. The bad entrepreneurs' projects are never successful, yielding an income of 0 points. The entrepreneurs can only repay a credit if they yield an income, meaning that only the good entrepreneurs are able to repay credits.

\footnotetext{
1 "K" stands for "Kreditgeber", the German of creditor, while "U" stands for "Unternehmer" the German for entrepreneur. 
The procedure in a credit market is the same in each period and is organized as follows:

\section{1) Information about the entrepreneurs in your sector}

There are one good and three bad entrepreneurs in each sector of the credit market. Which of the entrepreneurs is the good one will be randomly determined anew in each period. At the beginning of the period you only know which entrepreneur is good in your sector. You have no information about the entrepreneurs in the other three sectors of the credit market.

\section{2) Joining the information center}

In each period, you have the possibility of acquiring information about the entrepreneurs in the other sectors of the credit market. To do this, you must decide whether to join the information center for this period. If you join, you will be a member of the information center, for this period. As a member, you will learn from all the other members of the information center which entrepreneurs are good in their sectors. The other members of the information center will obviously also be informed which entrepreneur in your sector is good. If you choose not to join the information center, you will receive no information about the entrepreneurs in the other sectors, but no one will be informed about the entrepreneurs who are in your sector.

\section{3) Change of location by entrepreneurs:}

There is a chance in every period that the entrepreneurs will change their location. Random chance will decide whether the entrepreneurs remain in the same sector or if they move to another region. In the event of a change, the entrepreneurs move as a group from their original sector to a sector of another region (Example: U1-U4 move from Sector 1 to Sector 3).

\section{4) Credit offers}

After the location of the entrepreneurs has been determined, the credit phase begins. You as creditor can now make credit offers to a maximum of two entrepreneurs who are situated in your region. The amount of information you have about the entrepreneurs in your region depends on two factors: 1) whether the entrepreneurs moved and 2) whether you are a member of the information center.

Each creditor receives an endowment of 200 points in each period, with which he or she can make credit offers. A credit offer consists of a loan of 100 points and a repayment demand. The entrepreneurs are simulated by the computer and are programmed to automatically accept the credit offer with the lowest repayment. If your credit offer is accepted, you will only receive the repayment you demanded if the entrepreneur is good. Bad entrepreneurs never pay back.

\section{5) Income calculation:}

After the credit offers have been accepted, incomes are determined for this period. At the end of the experiment your income from all 20 periods will be added together, converted to Swiss francs, and paid out to you in cash, together with your show-up fee. 


\section{Detailed experiment procedures}

During the experiment you enter your decisions by computer. In the following, we show in detail how you can make your decisions in each period.

A total of twelve subjects participate in this experiment. All participants are creditors for the duration of the experiment. In each period there are three credit markets with four creditors each. The composition of the credit markets will be re-determined randomly at the beginning of each period. This means that you are with other creditors in the market in each period.

\section{$\underline{\text { 1. Information about entrepreneurs in your sector }}$}

(1.1) All credit markets have the same structure at the beginning of a period:

- There are four sectors (S1, S2, S3, S4) in each credit market, where two sectors each belong to the same region. Sectors 1 and 2 belong to region A and Sectors 3 and 4 belong to region B.

- There is a creditor in each sector (K1 in Sector 1, K2 in Sector 2, K3 in Sector 3, and K4 in Sector 4).

- There are 4 entrepreneurs in each sector (U1-U4 in Sector 1, U5-U8 in Sector 2, U9-U12 in Sector 3, und U13-U16 in Sector 4).

(1.2) In each period, the four participants of a credit market are assigned randomly to the four sectors. As a creditor, you will see which sector you are in at the beginning of each period on your screen (see the screen on the next page).

- At the top of the screen, you will see which period you are in.

- Below this, you will see which position you assume as creditor (K1, K2, K3 or K4).

- The area on the left of the screen provides a summary of the credit market. Sectors 1 and 2 are in region A and have a yellow background; sectors 3 and 4 in region B have a blue one.

- One creditor is represented in each sector. Your position as creditor is displayed in color.

(1.3) This screen also shows information about the entrepreneurs in your sector. There are two types of entrepreneurs, "good" entrepreneurs and "bad" entrepreneurs. The entrepreneurs have no equity of their own and each needs a credit of 100 points for the realization of a project.

- There is one good entrepreneur and three bad entrepreneurs in each sector.

- The projects of good entrepreneurs are always successful and yield an income of 300 points.

- The projects of bad entrepreneurs are never successful and yield an income of 0 points.

- Entrepreneurs can only repay a credit if they earn an income, implying that good entrepreneurs always pay back and bad entrepreneurs never pay back.

- On your screen you will see which entrepreneurs in your sector are "good" and which three entrepreneurs are "bad". The good entrepreneur appears in green, while the bad entrepreneurs appear in red.

- You will not see which entrepreneurs in the other sectors are good or bad; for this reason, these entrepreneurs all appear gray. 
(1.4) The three other creditors in the market also only receive information about the entrepreneurs in their own sectors. This means that the other creditors do not know which entrepreneur is good in your market.

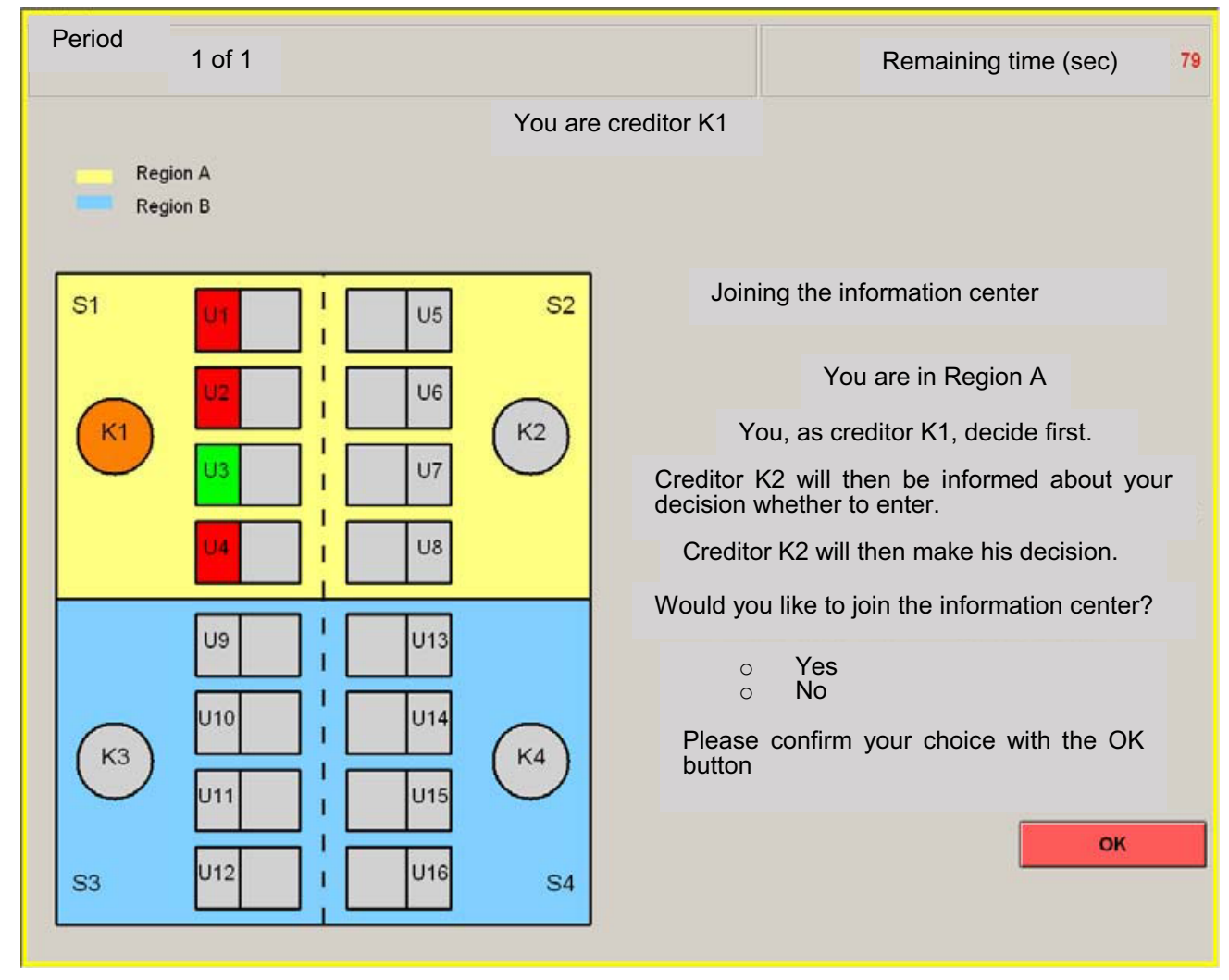

\section{Joining the information center}

(2.1) In each period you must decide whether you wish to join the information center in your market. For this purpose, the entry mask "Joining the information center" appears on the right side of your screen. You can now decide whether you want to become a member of the information center.

- If you press "yes", you will become a member of the information center in this period. In this case, the other members of the information center will be informed which entrepreneur in your sector is good and which are bad. In return, you will be informed which entrepreneurs in the sectors of the other members are good and which are bad.

- If you press "no", you will not become a member of the information center in this period. In this case, no information about the entrepreneurs in your sector will be available in the information center. However, you will not receive any information about the entrepreneurs in the other sectors.

- Within a region, the two creditors decide after one another whether they wish to join the information center. The order of the decision is determined randomly in each period. If you are the second creditor in your region, you will be informed whether the other creditor in your region has already joined before making your decision. 
- You will not be informed whether the other creditors from the other regions joined the information center until all creditors have made their decisions.

- Membership in the information center bears no cost for any creditor.

(2.2) As soon as all creditors have decided whether they wish to join, you will see which creditors have joined the information center on the right side of your screen. If you are a member of the information center, you will also be informed which entrepreneurs in the other members' sectors are good and which are bad. In this case, good entrepreneurs appear in green and bad entrepreneurs are red. If you have no information about entrepreneurs, they remain gray. If you are not a member of the information center, you will receive no information about the entrepreneurs in the other sectors.

Example 1: You are creditor K1, and you join the information center. Creditors $\mathrm{K} 2$ and $\mathrm{K} 4$ also join, but creditor K3 does not. In this case, after your decision to join, you will be informed which of the following entrepreneurs are good or bad: U1-U4, U5-U8, U13-U16. You still have no information about entrepreneurs U9 - U12. Creditors K2 and K4 have the same information as you do, while creditor K3 only knows about entrepreneurs U9 - U12.

Example 2: You are creditor K1, and you do NOT join the information center, while creditors $\mathrm{K} 2, \mathrm{~K} 3$, and $\mathrm{K} 4$ enroll. In this case, you only know about the entrepreneurs in your own sector, meaning that you only know which entrepreneur from U1 - U4 is good. You have no information about any other entrepreneurs. Creditors K2, K3, and K4 are informed abut all entrepreneurs U5U8, U9-U12 and U13-U16. However, they do not know which entrepreneur is good in your sector. 


\section{Change of location for entrepreneurs}

(3.1) In every period, there is a chance that the entrepreneurs will change their location.

- There is a probability of $3 / 4$ that all entrepreneurs will change their regions. In this case, all entrepreneurs in Region A change to Region B, and all entrepreneurs in Region B change to Region A. When the entrepreneurs change location, they change in groups: U1-U4 move to Sector 3, U5-U8 to Sector 4, U9-U12 to Sector 1, and U13-U16 to Sector 2 (see the screen below). It is thus clear that after changing locations there is still one good entrepreneur and three bad entrepreneurs in each sector.

- There is a probability of $1 / 4$ that all entrepreneurs remain in their original sectors.

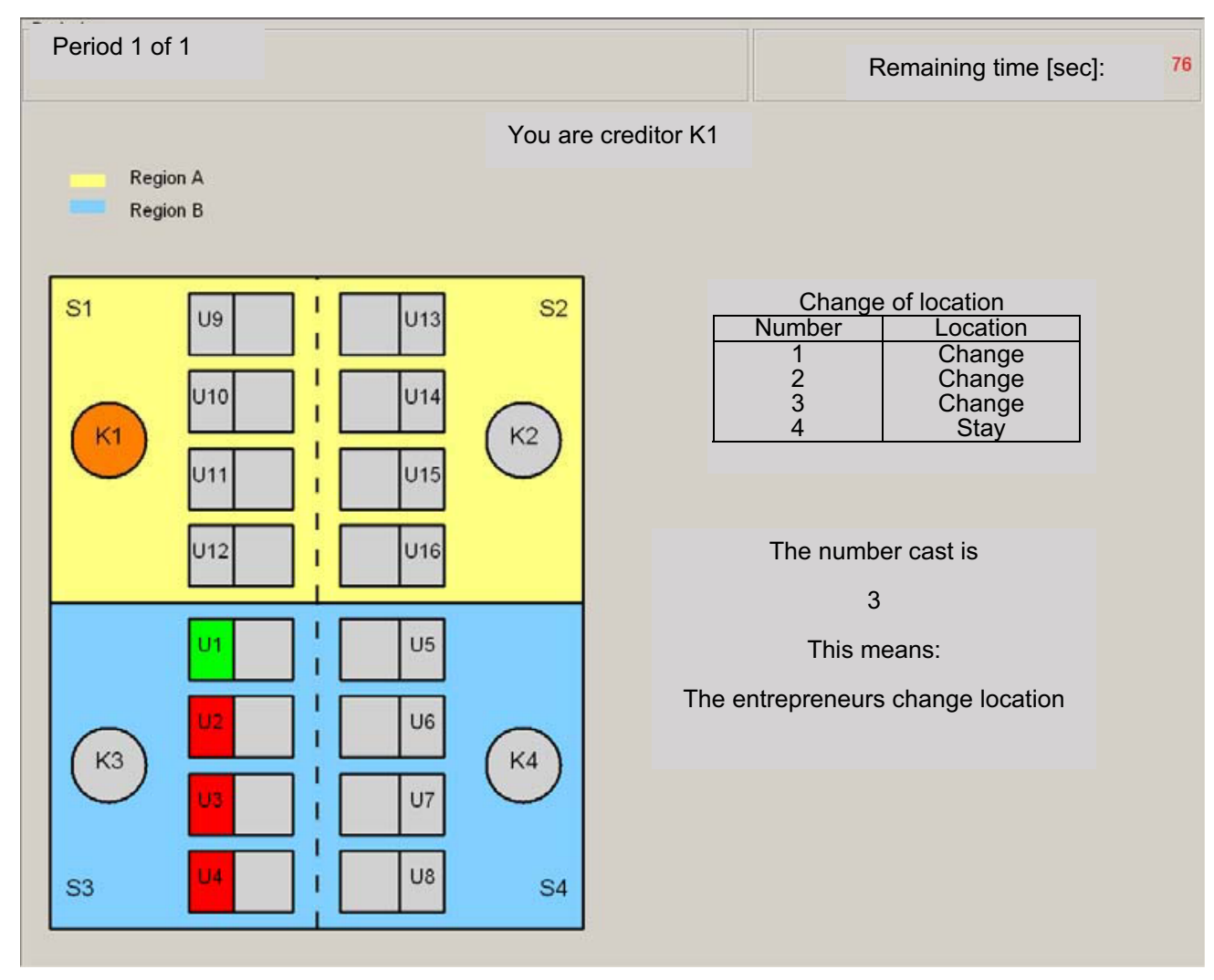

(3.2) The roll of a dice determines in each period whether the entrepreneurs change location or not. The field "change of location" appears at the right on your screen for this purpose. You see a list with three numbers in this field $(1,2,3,4)$. To the right of each number "change" or "stay" appears, meaning that "stay" is next to one number and "change" is next to three numbers. The number which has "stay" next to it is determined separately for each of the three credit markets in each period. This allocation applies to all four participants in a credit market. After the number list appears on your screen, a participant in the experiment casts a four-sided die in order to determine which random number applies for this period. The number rolled will then be announced aloud. You will immediately see the effects of this number on your credit market, i.e. 
whether all entrepreneurs remain in their original sector or if they change regions. When the entrepreneurs change, they will be moved directly into the new sectors on your screen.

(3.3) The screen shown above presents an example where the entrepreneurs change their regions. The number cast is three. The table shows that the number 3 stands for "change" in this credit market.

(3.3) The information you as creditor have about the entrepreneurs will not be influenced by a change of location. You know before or after any change of location whether the same entrepreneurs are good or bad.

\section{Credit Phase}

(4.1) The credit phase begins after it has been determined whether the entrepreneurs change location or not. In this phase, you can make credit offers to a maximum of 2 entrepreneurs in your region. You have a capital of 200 points for this purpose in each period.

(4.2) During the credit phase you will see the screen displayed below:

- The credit phase in each period lasts for a total of 90 seconds. The numbers on the upper right side of your screen indicate how long the credit phase will last.

- The left side of your screen provides a summary of all entrepreneurs in your region. If you have information about entrepreneurs, either because the entrepreneurs were originally in your sector or because you are a member of the information center, this information is again presented using the colors green (for good entrepreneurs) and red (for bad entrepreneurs). Entrepreneurs for whom you have no information are presented in gray.

- You can now make credit offers to the entrepreneurs in your region. You must decide whether you wish to make an offer to each entrepreneur in your region. For this purpose each entrepreneur in your region has two fields. You must choose between "A" for "offer" and "K" for "no offer". ${ }^{2}$

\footnotetext{
- ${ }^{2}$ "A" stands for "Angebot", the German for "offer", "K" stands for "kein Angebot", the German for "no offer".
} 


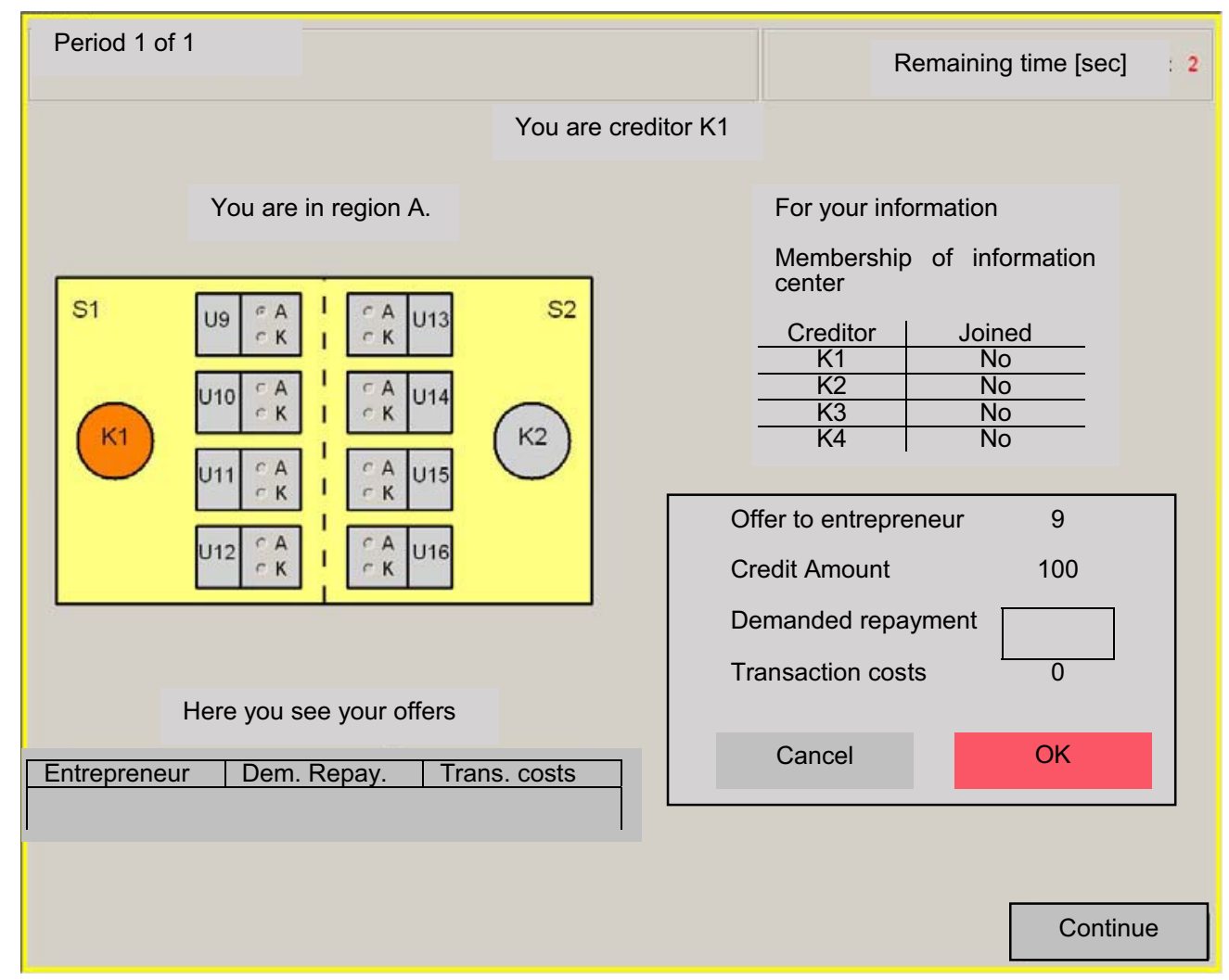

(4.3) If you want to make a credit offer to an entrepreneur, click on the field "A" next to this entrepreneur. The entry mask for the credit offer will now appear on the right.

- The credit amount is always 100 points.

- You must determine the amount of the demanded repayment. Please take note that the minimum repayment is 100 points and the maximum is 300 points.

\section{$100 \leq$ demanded repayment $\leq 300$}

(4.4) The credit offer is complete after you have determined the demanded repayment. You can now click the "OK" button to conclude the offer. You can not change any concluded offer after pressing the "OK" button. If you have not yet pressed this button, you can change your offer or cancel it with the "cancel" button.

(4.5) Every credit offer you make appears in a list at the bottom of your screen. You will see to which entrepreneurs you have made an offer and how high your demanded repayment is. During the credit phase, no other creditor will be informed about the offers you have made. You will also not be informed which credit offers other creditors have made.

(4.6) You can make a maximum of two credit offers in each period. However, you are not required to make credit offers. If you do not want to make a credit offer to an entrepreneur in your region, then choose "K" for this entrepreneur. You must either make an offer or click "K" for every entrepreneur in your region. You can only then conclude your offers with "continue". 
(4.7) As soon as all creditors have made their credit offers, the entrepreneurs choose one. We have programmed the entrepreneurs so that they always accept the lowest repayment:

- If an entrepreneur only receives a credit offer from one creditor in his region, he will accept this in any case.

- If he receives an offer from both creditors in his region, he will choose the offer with the lowest demanded repayment. If both demanded repayments are equally high, he will chose the credit offer from the entrepreneur located in his sector.

(4.8) If one of your credit offers is accepted, you must bear the transaction costs for concluding the credit. The following rule applies in this case:

- Transaction costs for an entrepreneur located in your sector amount to 0 points.

- Transaction costs for an entrepreneur who is not located in your sector are 160 points.

If a credit offer is not accepted, you do not have to pay any transaction costs.

\section{Transaction costs $=$}

\section{0 if the entrepreneur is in your sector.}

160 if the entrepreneur is not in your sector.

(4.9) As soon as the credit offers are accepted, you will see which offers were made by you and by the other creditors in your region on your screen (see screen below).

- The right side of your screen shows which credit offers were made for each entrepreneur in your region, either by you or by the other creditors, and which offers each entrepreneur accepted.

- The left side of the screen gives a presentation of your region, showing whether the entrepreneurs in your region are good (green) or bad (red).

(4.10) Your income is calculated at the bottom of your screen. If one of your credit offers was accepted, this area will show you the repayment you received from this credit and your credit income from this contract. However, you will only receive your demanded repayment if the entrepreneur is good. If the entrepreneur who accepted the credit is bad, he earns no income. Bad entrepreneurs can thus make no repayment.

Actual repayment $=$ if the entrepreneur is good

if the entrepreneur is bad

The next section shows how your total income in each period is calculated in detail. 


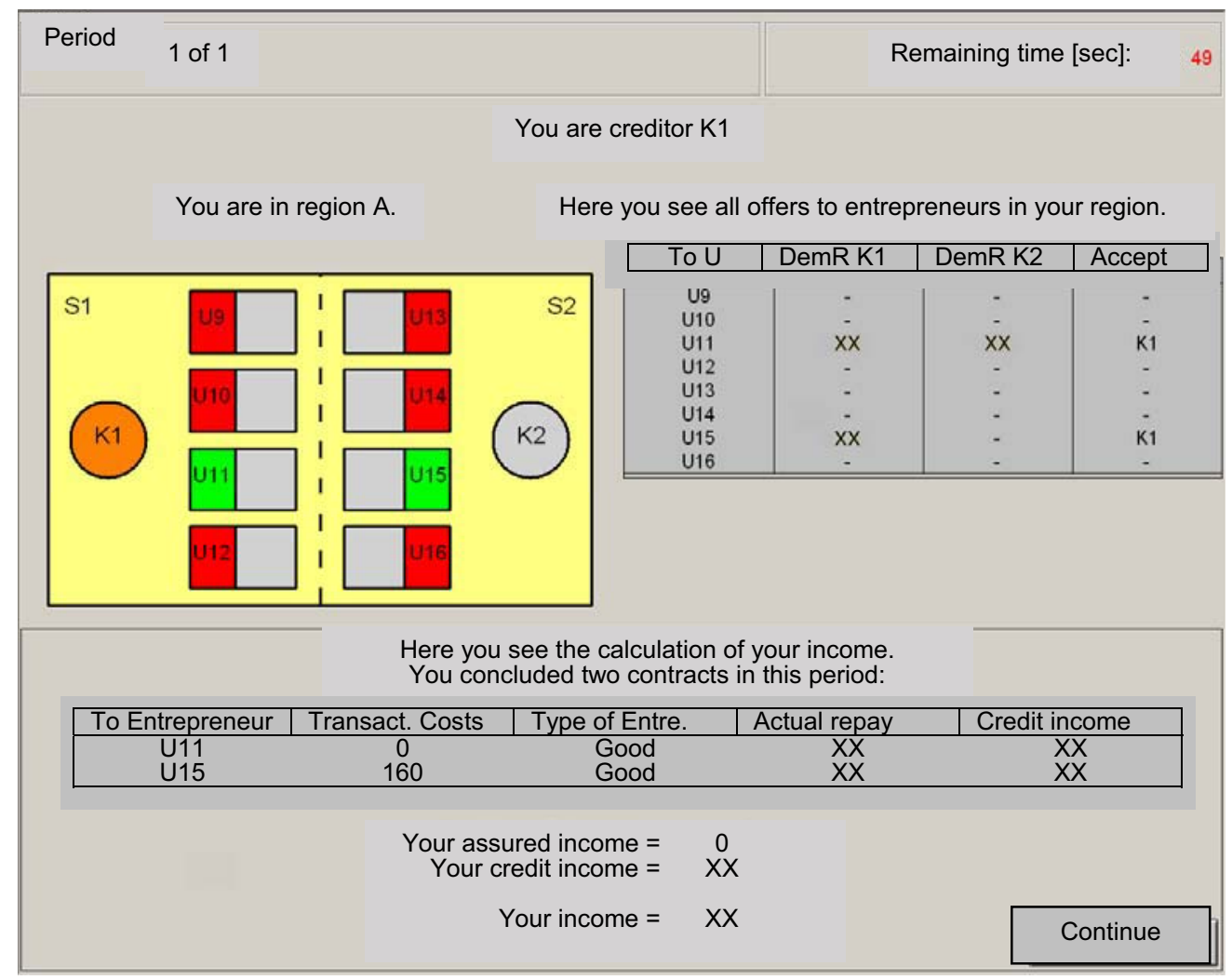

\section{Calculation of income}

(5.1) As soon as all credit offers have been accepted, the income for all creditors in this period will be determined. Creditors' incomes are all determined in the same way.

(5.2) Your income as a creditor consists of your certain income and your credit income. Your certain income corresponds to that part of your capital which you did not use for extending credit. If you did not conclude any credits, you earn a certain income of 200 points.

\section{Your certain income $=\mathbf{2 0 0}-$ credits}

(5.3) If you concluded credits, your credit income corresponds to your actual repayments minus the transaction costs.

\section{Your credit income $=$ actual repayments - transaction costs}

(5.4) Your total income in a period is the sum of your certain income and credit income. Your total income thus depends on which credits you have concluded and whether the entrepreneur could make the repayment.

\section{Your income $=\mathbf{2 0 0}-$ credits + actual repayments - transaction costs}


Example 1: You only made one credit offer in a period. Your offer goes to an entrepreneur located in your sector whom you know to be good. Your demanded repayment is 200 points. The other creditor makes no offer to this entrepreneur. The entrepreneur therefore accepts your offer. Your certain income is $200-100=100$ points, as you only concluded one credit. As the entrepreneur is good, he will make your demanded repayment. You do not have to pay any transaction costs, as the entrepreneur is in your sector. Your credit income thus amounts to 200 points. Your total income equals 300 points.

Example 2: You only made one credit offer in a period. Your offer goes to an entrepreneur located in your sector whom you know to be good. Your demanded repayment amounts to 200 points. The other creditor also makes an offer to this entrepreneur and demands a repayment of 150. The entrepreneur accepts the other creditor's offer. Your certain income is 200 points, as you did not conclude a credit. Your credit income is 0 points. Your total income is thus 200 points.

Example 3: You only made one credit offer to an entrepreneur in the other sector of your region, and you do not know if this entrepreneur is good or bad. Your demanded repayment is 200 points. The other creditor in your region also makes an offer to this entrepreneur and demands a repayment of 250. The entrepreneur accepts your offer. Your certain income is $200-100=100$ points, as you concluded one credit. You pay transaction costs of 160 points, as the entrepreneur is in the other sector. If the entrepreneur is good, your credit income will thus amount to $200-$ $160=40$ points (and your total income is therefore 140 points). If the entrepreneur is bad, your credit income will amount to $0-160=-160$ points (and your total income is therefore -60 points).

(5.6) Please note that as a creditor you can earn negative incomes in every period. This can happen if you make offers to bad creditors. You can always avoid negative incomes with your own decisions. If you earn negative incomes, you must pay these with points earned in earlier periods or, if necessary, with your show-up fee.

(5.7) The experiment lasts for 20 periods, and the procedure is the same in all periods. In each period, you will be assigned randomly to a credit market with three other participants. It will also be randomly determined in each period which entrepreneur in each sector of the credit market is good and which entrepreneurs are bad.

(5.8) The experiment will not begin until all participants are completely familiar with the experimental procedures. In order to make sure of this, we ask you to answer some control questions below. 


\section{Exercises}

Please answer these questions fully, showing the detailed steps of your solution. If you have questions, please contact the experimenter. Wrong answers have no consequences for you.

\section{Question 1}

You are creditor K1. The other creditor in your region (K2) has decided to join the information center. Both creditors in the other region join the information center. The entrepreneurs REMAIN in their original locations.

a) You decide not to join the information center.

Which entrepreneurs in your region do you know to be good (or bad)?

\begin{tabular}{|l|l|l|l|}
\hline U1 & U2 & U3 & U4 \\
\hline & & & \\
\hline
\end{tabular}

\begin{tabular}{|l|l|l|l|}
\hline U5 & U6 & U7 & U8 \\
\hline & & & \\
\hline
\end{tabular}

Which entrepreneurs in your region does creditor K2 know to be good (or bad)?

\begin{tabular}{|l|l|l|l|}
\hline U1 & U2 & U3 & U4 \\
\hline & & & \\
\hline
\end{tabular}

\begin{tabular}{|l|l|l|l|}
\hline U5 & U6 & U7 & U8 \\
\hline & & & \\
\hline
\end{tabular}

b) How does the information constellation change if you join the information center?

Which entrepreneurs in your region do you know to be good (or bad)?

\begin{tabular}{|l|l|l|l|}
\hline U1 & U2 & U3 & U4 \\
\hline & & & \\
\hline
\end{tabular}

\begin{tabular}{|l|l|l|l|}
\hline U5 & U6 & U7 & U8 \\
\hline & & & \\
\hline
\end{tabular}

Which entrepreneurs in your region does creditor K2 know to be good (or bad)?

\begin{tabular}{|l|l|l|l|}
\hline U1 & U2 & U3 & U4 \\
\hline & & & \\
\hline
\end{tabular}

\begin{tabular}{|l|l|l|l|}
\hline U5 & U6 & U7 & U8 \\
\hline & & & \\
\hline
\end{tabular}

\section{Question 2}

You are creditor K1. The other creditor in your region (K2) has decided to join the information center. Both creditors in the other region join the information center. The entrepreneurs CHANGE their original locations.

a) You decide not to join the information center.

Which entrepreneurs in your region do you know to be good (or bad)?

\begin{tabular}{|l|l|l|l|}
\hline U9 & U10 & U11 & U12 \\
\hline & & & \\
\hline
\end{tabular}

\begin{tabular}{|l|l|l|l|}
\hline U13 & U14 & U15 & U16 \\
\hline & & & \\
\hline
\end{tabular}


Which entrepreneurs in your region does creditor K2 know to be good (or bad)?

\begin{tabular}{|l|l|l|l|}
\hline U9 & U10 & U11 & U12 \\
\hline & & & \\
\hline
\end{tabular}

\begin{tabular}{|l|l|l|l|}
\hline U13 & U14 & U15 & U16 \\
\hline & & & \\
\hline
\end{tabular}

b) How does the information constellation change if you join the information center?

Which entrepreneurs in your region do you know to be good (or bad)?

\begin{tabular}{|l|l|l|l|}
\hline U1 & U2 & U3 & U4 \\
\hline & & & \\
\hline
\end{tabular}

\begin{tabular}{|l|l|l|l|}
\hline U5 & U6 & U7 & U8 \\
\hline & & & \\
\hline
\end{tabular}

Which entrepreneurs in your region does creditor K2 know to be good (or bad)?

\begin{tabular}{|l|l|l|l|}
\hline U1 & U2 & U3 & U4 \\
\hline & & & \\
\hline
\end{tabular}

\begin{tabular}{|l|l|l|l|}
\hline U5 & U6 & U7 & U8 \\
\hline & & & \\
\hline
\end{tabular}

\section{Question 3}

You are creditor K1. The other creditor in your region (K2) has decided NOT to join the information center. Both creditors in the other region join the information center. The entrepreneurs REMAIN in their original locations.

a) You decide not to join the information center.

Which entrepreneurs in your region do you know to be good (or bad)?

\begin{tabular}{|l|l|l|l|}
\hline U9 & U10 & U11 & U12 \\
\hline & & & \\
\hline
\end{tabular}

\begin{tabular}{|l|l|l|l|}
\hline U13 & U14 & U15 & U16 \\
\hline & & & \\
\hline
\end{tabular}

Which entrepreneurs in your region does creditor K2 know to be good (or bad)?

\begin{tabular}{|l|l|l|l|}
\hline U9 & U10 & U11 & U12 \\
\hline & & & \\
\hline
\end{tabular}

\begin{tabular}{|l|l|l|l|}
\hline U13 & U14 & U15 & U16 \\
\hline & & & \\
\hline
\end{tabular}

b) How does the information constellation change if you join the information center?

Which entrepreneurs in your region do you know to be good (or bad)?

\begin{tabular}{|l|l|l|l|}
\hline U1 & U2 & U3 & U4 \\
\hline & & & \\
\hline
\end{tabular}

\begin{tabular}{|l|l|l|l|}
\hline U5 & U6 & U7 & U8 \\
\hline & & & \\
\hline
\end{tabular}

Which entrepreneurs in your region does creditor K2 know to be good (or bad)?

\begin{tabular}{|l|l|l|l|}
\hline U1 & U2 & U3 & U4 \\
\hline & & & \\
\hline
\end{tabular}

\begin{tabular}{|l|l|l|l|}
\hline U5 & U6 & U7 & U8 \\
\hline & & & \\
\hline
\end{tabular}




\section{Question 4}

You are creditor K1. The other creditor in your region (K2) has decided NOT to join the information center. Both creditors in the other region join the information center. The entrepreneurs CHANGE their original locations.

a) You decide not to join the information center.

Which entrepreneurs in your region do you know to be good (or bad)?

\begin{tabular}{|l|l|l|l|}
\hline U9 & U10 & U11 & U12 \\
\hline & & & \\
\hline
\end{tabular}

\begin{tabular}{|l|l|l|l|}
\hline U13 & U14 & U15 & U16 \\
\hline & & & \\
\hline
\end{tabular}

Which entrepreneurs in your region does creditor K2 know to be good (or bad)?

\begin{tabular}{|l|l|l|l|}
\hline U9 & U10 & U11 & U12 \\
\hline & & & \\
\hline
\end{tabular}

\begin{tabular}{|l|l|l|l|}
\hline U13 & U14 & U15 & U16 \\
\hline & & & \\
\hline
\end{tabular}

b) How does the information constellation change if you join the information center?

Which entrepreneurs in your region do you know to be good (or bad)?

\begin{tabular}{|l|l|l|l|}
\hline U1 & U2 & U3 & U4 \\
\hline & & & \\
\hline
\end{tabular}

\begin{tabular}{|l|l|l|l|}
\hline U5 & U6 & U7 & U8 \\
\hline & & & \\
\hline
\end{tabular}

Which entrepreneurs in your region does creditor K2 know to be good (or bad)?

\begin{tabular}{|l|l|l|l|}
\hline U1 & U2 & U3 & U4 \\
\hline & & & \\
\hline
\end{tabular}

\begin{tabular}{|l|l|l|l|}
\hline U5 & U6 & U7 & U8 \\
\hline & & & \\
\hline
\end{tabular}




\section{Question 5}

You made no credit offer. How high is your income in the period in question?

Your certain income $=$

Your credit income $=$

Your total income $=$

\section{Question 6}

You concluded a credit with an entrepreneur located in your sector; you do not know if he is a good or a bad entrepreneur. Your demanded repayment is 200 points.

a) How high is your income in the period in question if the entrepreneur is good?

$$
\begin{aligned}
& \text { Your certain income }= \\
& \text { Your credit income }= \\
& \text { Your total income }=
\end{aligned}
$$

b) How high is your income in the period in question if the entrepreneur is bad?

$$
\begin{aligned}
& \text { Your certain income }= \\
& \text { Your credit income }= \\
& \text { Your total income }=
\end{aligned}
$$

\section{Question 7}

You concluded a credit with an entrepreneur located outside of your sector; you do not know if he is a good or a bad entrepreneur. Your demanded repayment is 200 points.

a) How high is your income in the period in question if the entrepreneur is good?

$$
\begin{aligned}
& \text { Your certain income }= \\
& \text { Your credit income }= \\
& \text { Your total income }=
\end{aligned}
$$

b) How high is your income in the period in question if the entrepreneur is bad?

$$
\begin{aligned}
& \text { Your certain income }= \\
& \text { Your credit income }= \\
& \text { Your total income }=
\end{aligned}
$$




\section{Question 8}

You have made a credit offer. The offer is for the good entrepreneur in your sector. Your demanded repayment is 300 points.

a) The other creditor in your region makes no credit offer to this entrepreneur. How high is your income in this period?

$$
\begin{aligned}
& \text { Your certain income }= \\
& \text { Your credit income }= \\
& \text { Your total income }=
\end{aligned}
$$

b) The other creditor in your region offers this entrepreneur a credit with a demanded repayment of 150 points. How high is your income in this period?

$$
\begin{aligned}
& \text { Your certain income }= \\
& \text { Your credit income }= \\
& \text { Your total income }=
\end{aligned}
$$

\section{Question 9}

You have made a credit offer. The offer is for the good entrepreneur in the other sector of your region. Your requested repayment is 300 points.

a) The other creditor in your region makes no credit offer to this entrepreneur. How high is your income in the period in question?

\section{Your certain income $=$ Your credit income $=$$$
\text { Your total income }=
$$

b) The other creditor in your region offers this entrepreneur a credit with a demanded repayment of 150 points. How high is your income in the period in question?

$$
\begin{aligned}
& \text { Your certain income }= \\
& \text { Your credit income }= \\
& \text { Your total income }=
\end{aligned}
$$

When you have finished solving these exercises, we advise you to red through the questions and your solutions again. We then suggest that you consider which decisions you wish to make in the experiment. 


\section{Swiss National Bank Working Papers published since 2004:}

2004-1 Samuel Reynard: Financial Market Participation and the Apparent Instability of Money Demand

2004-2 Urs W. Birchler and Diana Hancock: What Does the Yield on Subordinated Bank Debt Measure?

2005-1 Hasan Bakhshi, Hashmat Khan and Barbara Rudolf: The Phillips curve under state-dependent pricing

2005-2 Andreas M. Fischer: On the Inadequacy of Newswire Reports for Empirical Research on Foreign Exchange Interventions

2006-1 Andreas M. Fischer: Measuring Income Elasticity for Swiss Money Demand: What do the Cantons say about Financial Innovation?

2006-2 Charlotte Christiansen and Angelo Ranaldo: Realized Bond-Stock Correlation: Macroeconomic Announcement Effects

2006-3 Martin Brown and Christian Zehnder: Credit Reporting, Relationship Banking, and Loan Repayment

2006-4 Hansjörg Lehmann and Michael Manz: The Exposure of Swiss Banks to Macroeconomic Shocks - an Empirical Investigation

2006-5 Katrin Assenmacher-Wesche and Stefan Gerlach: Money Growth, Output Gaps and Inflation at Low and High Frequency: Spectral Estimates for Switzerland

2006-6 Marlene Amstad and Andreas M. Fischer: Time-Varying Pass-Through from Import Prices to Consumer Prices: Evidence from an Event Study with Real-Time Data

2006-7 Samuel Reynard: Money and the Great Disinflation

2006-8 Urs W. Birchler and Matteo Facchinetti: Can bank supervisors rely on market data? A critical assessment from a Swiss perspective

2006-9 Petra Gerlach-Kristen: A Two-Pillar Phillips Curve for Switzerland

2006-10 Kevin J. Fox and Mathias Zurlinden: On Understanding Sources of Growth and Output Gaps for Switzerland

2006-11 Angelo Ranaldo: Intraday Market Dynamics Around Public Information Arrivals

2007-1 Andreas M. Fischer, Gulzina Isakova and Ulan Termechikov: Do FX traders in Bishkek have similar perceptions to their London colleagues? Survey evidence of market practitioners' views 
2007-2 Ibrahim Chowdhury and Andreas Schabert: Federal Reserve Policy viewed through a Money Supply Lens

2007-3 Angelo Ranaldo: Segmentation and Time-of-Day Patterns in Foreign Exchange Markets

2007-4 Jürg M. Blum: Why `Basel II’ May Need a Leverage Ratio Restriction

2007-5 Samuel Reynard: Maintaining Low Inflation: Money, Interest Rates, and Policy Stance

2007-6 Rina Rosenblatt-Wisch: Loss Aversion in Aggregate Macroeconomic Time Series

2007-7 Martin Brown, Maria Rueda Maurer, Tamara Pak and Nurlanbek Tynaev: Banking Sector Reform and Interest Rates in Transition Economies: Bank-Level Evidence from Kyrgyzstan

2007-8 Hans-Jürg Büttler: An Orthogonal Polynomial Approach to Estimate the Term Structure of Interest Rates

2007-9 Raphael Auer: The Colonial Origins Of Comparative Development: Comment. A Solution to the Settler Mortality Debate

2007-10 Franziska Bignasca and Enzo Rossi: Applying the Hirose-Kamada filter to Swiss data: Output gap and exchange rate pass-through estimates

2007-11 Angelo Ranaldo and Enzo Rossi: The reaction of asset markets to Swiss National Bank communication

2007-12 Lukas Burkhard and Andreas M. Fischer: Communicating Policy Options at the Zero Bound

2007-13 Katrin Assenmacher-Wesche, Stefan Gerlach, and Toshitaka Sekine: Monetary Factors and Inflation in Japan

2007-14 Jean-Marc Natal and Nicolas Stoffels: Globalization, markups and the natural rate of interest

2007-15 Martin Brown, Tullio Jappelli and Marco Pagano: Information Sharing and Credit: Firm-Level Evidence from Transition Countries

2007-16 Andreas M. Fischer, Matthias Lutz and Manuel Wälti: Who Prices Locally? Survey Evidence of Swiss Exporters

2007-17 Angelo Ranaldo and Paul Söderlind: Safe Haven Currencies 
2008-1 Martin Brown and Christian Zehnder: The Emergence of Information Sharing in Credit Markets 
Swiss National Bank Working Papers are also available at www.snb.ch, section Publications/Research Subscriptions or individual issues can be ordered at Swiss National Bank, Fraumünsterstrasse 8, CH-8022 Zurich, fax+41 4463181 14, E-mail library@snb.ch 